\title{
Quantification of additive manufacturing induced variations in the global and local performance characteristics of a complex multi-stage control valve trim
}

\author{
Dharminder Singh $^{\mathrm{a}}$, Matthew Charlton ${ }^{\mathrm{b}}$, Taimoor Asim ${ }^{\mathrm{c}}$, Rakesh Mishra ${ }^{\mathrm{a}}$, \\ Andrew Townsend ${ }^{\mathrm{a}}$, Liam Blunt ${ }^{\mathrm{a}}$ \\ ${ }^{a}$ School of Computing \& Engineering, University of Huddersfield, Queensgate, Huddersfield HD1 3DH, United \\ Kingdom \\ ${ }^{b}$ Previously Manager of Product Development, Trillium Flow Technologies, Britannia House, Huddersfield \\ Road, Elland HX5 9JR, United Kingdom \\ ${ }^{c}$ School of Engineering, Robert Gordon University, Garthdee Road, Aberdeen AB10 7GJ, United Kingdom
}

\begin{abstract}
Control valves that are used in severe service applications have trim cages that are geometrically quite complex. Most of these trims are manufactured using traditional manufacturing methods which are expensive and time-consuming. In order to reduce manufacturing costs and shorten the product development cycles, Additive Manufacturing (AM) methods have been gaining popularity over the traditional manufacturing methods. Selective Laser Melting (SLM) is one of the most popular AM techniques. In this paper, the effect of the conventional Electron Discharge Machining (EDM) method and the SLM method on the performance characteristics of a complex multi-stage disc stack trim is investigated. Experimental tests conducted on the SLM trim showed that the flow capacity reduced in comparison to the EDM manufactured trim. Surface profile measurements indicated that the surface roughness of the SLM trim was significantly higher than the EDM trim. In order to evaluate the effect of surface roughness on performance in detail, well validated numerical simulations were conducted to compare the local performance of the valve trims manufactured by the two methods. The simulation results showed that the wall shear stress increases by 1.9 times on the trim manufactured by the SLM method due to the increased roughness.
\end{abstract}

Keywords: Additive manufacturing; Selective laser melting; Control valves; Surface roughness; Computation Fluid Dynamics (CFD); Flow capacity

\section{Introduction}

Control valves are one of the most critical and complex components of process control systems. They are designed to control process parameters such as flow rate, pressure, temperature, etc. The components of a control valve are shown in Fig. 1. Flow control is achieved by varying the flow area by controlling the position of a plug against a seat inside a cage/stack. The cage is composed of a number of discs stacked together that incorporate provisions for complex fluid flow paths on their surface. This is achieved by incorporating well designed obstructions in the flow paths to induce a controlled amount of energy loss. The discs are designed to provide pressure drop in a number of stages, where the flow area is expanded after the pressure drop at each stage and effectively reducing the fluid velocity across the surface of the disc in order to prevent problems like noise, cavitation and erosion. There have been significant developments in the design of severe service control valves over the past two decades from their initial concept designs. As the number of services that require these type of control valves continues to increase and due to the associated costs of 
production, there has been a significant drive to reduce manufacturing costs for these products.

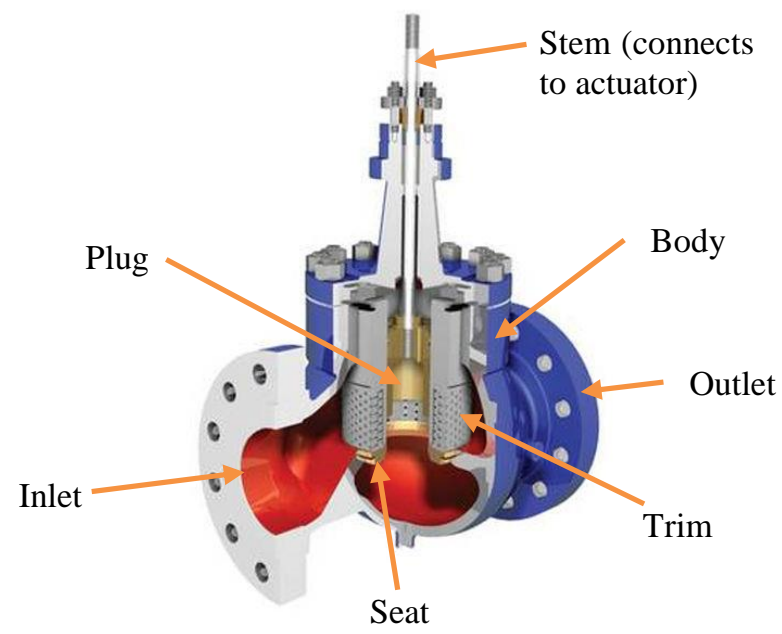

Fig. 1: Components of a control valve body with trim

Traditionally, the disc stack trims have been manufacturing using EDM [1]. Due to the complexity of the flow paths on the trim, the EDM method of manufacture is quite costly and it can take up to 10 weeks to manufacture a disc stack. The higher lead manufacturing time limits the new equipment delivery, as well as the spares replacements [2].

Due to the increasing demand for customised and personalised products, the manufacturing industry has been seeking new manufacturing methods/techniques to shorten product development timescales [3]. In order to overcome the limitations of the traditional manufacturing methods, Additive Manufacturing has been gaining popularity over the last three decades. The advantage of AM methods is reduction in manufacturing costs and lead times. A number of AM technologies have been developed, such as Electron Beam Melting, Selective Laser Melting, Laser Metal Deposition, Metal Binder Jetting, Hybrid Laser Deposition Welding and Milling [4,5]. Among these methods, Selective Laser Melting is known to print complex parts accurately with high density and improved mechanical properties and [5]. In the past, SLM has been used effectively for rapid prototyping and product development, however, the development of high powered lasers and general process optimisation has led to the use of SLM for general production of parts. However, there is a need to develop dedicated systems that can be used to optimise the post-manufacture finishing processes [6].

There are various process parameters that have significant impact on the mechanical properties of SLM manufactured parts. These parameters include hatch spacing, build speed, laser spot size, laser power, point distance, powder layer thickness, and exposure time. Enneti et al. [7] investigated the effect of hatch spacing and build speed on the density of tungsten parts. The hatch spacings they investigated were 15 and $30 \mu \mathrm{m}$ while the build speeds were in the range of 200 to $1400 \mathrm{~mm} / \mathrm{s}$. Their findings revealed that using smaller hatch spacing and slower scan speeds produced denser parts. The effect of build speed was more dominant than the hatch spacing. Hanzl et al. [8] conducted investigation of different SLM manufacturing parameters and found that the build speed and laser power settings have a high impact on the mechanical and physical properties of the SLM manufactured component. Furthermore, they also studied the impact of the build direction. Their results showed that the parts manufactured along the vertical axis tend to have higher tensile strength than those 
manufactured along the horizontal axis. Building at an angle of less than $45^{\circ}$ caused delamination of the layers and deteriorated the components' mechanical properties.

Osakada and Shiomi [9] investigated the deformation of SLM manufactured parts caused by thermal distortion using Finite Element Analysis. Their findings show that there is an increase in the degree of thermal distortion of a single layer with increase in the length of scanning track and thus, there is an increase in the maximum tensile stress. They suggested that during the formation of a large layer on the powder bed, the forming area should be divided into a number of small segments. Rapid heating and cooling of the part induces residual stresses within the part. Osakada and Shiomi [9] discovered that residual tensile stresses have a large effect on the deformities produced on the manufactured part. They also found large residual tensile stresses are present in the top layers of the model which decrease rapidly as the distance from the model's top surface increases. Based on these findings, the authors suggested that re-scanning during each layer formation can reduce the residual stresses. This provides more optimised control over the applied heat on the component, thus the manufacturing speed reduces and rapid heating is prevented. Build speed is, therefore, a very important parameter that needs to be considered, especially when manufacturing parts with greater heights from the base plate.

It is evident from the published literature [10-12] that the surface finish of a manufactured part depends on the method of manufacture. Due to the nature of the surface finish, the roughness of the surface varies depending on the manufacturing method used. The variation in surface roughness affects the flow parameters and performance of control valves as these valves have many intricate geometric features [13]. As control valves are an important component of flow handling systems, their performance affects the efficiency of the flow handling systems. Thus, it is necessary to evaluate the performance of control valves in order to maintain/improve the efficiency of the flow handling systems.

Some authors have conducted some research studies recently where they have analysed the flow behaviour in such geometrically complex trims. Green et al [14] conducted 2-D CFD simulations on a disc quarter of a disc stack trim and compared the results with the experimentally obtained data. Their simulations resulted in $25 \%$ higher valve flow capacity as compared to the experiments. The reason for this difference can be attributed to the significant simplification of the complete disc to a quarter of the disc. Surface roughness was not modelled in their simulations as the trim disc used in this study was considered to be hydrodynamically smooth. Asim et al [15-17] and Oliveira [18] adopted the approach of 3-D simulations to conduct CFD simulations on the full three-dimensional body of the valve. These simulations showed very close agreement with the results from the experimental testing. They have reported that the flow capacity of the control valves is independent of the flow conditions and it depends on the valve opening position (VOP) only. As the VOP increases, there is an increase in the flow capacity of the valve. Asim et al [15-17] conducted studies on the variation of pressure and velocity within the trim and highlighted the importance of local flow analysis within the trim which could be used for the development of better designs of the trim. They observed that cavitation may occur in the flow paths within the trim as the local static pressure at some locations around the cylinders may drop below the vapour pressure under extreme conditions of operation. The trim used in their study was EDM manufactured and had a surface roughness of $0.5 \mathrm{~mm}$. Sun et al [19] investigated the effect of surface roughness on the flow capacity of a valve. They found that surface roughness reduced the performance of a fully opened valve by up to $17 \%$. They also state that with an increase in the VOP, as the flow rate increases, the pressure loss resulting from friction also increases rapidly. Thus, surface roughness is an important factor that can affect 
the performance of a valve. Singh et al [20] investigated the effect of design changes to assist the additive manufacturing process of SLM in order to improve the performance of the control valve trims. However, the performance evaluation was carried out only at the global level but not at the local level.

The purpose of the present study is to critically evaluate the performance characteristics of the valve trim which has been manufactured by the SLM method and compare its performance to the trim manufactured using the EDM method with a view to establish the effectiveness of the AM methods' usefulness for complex valve trims. The performance of the trims has been evaluated at both global and local level. In order to evaluate the global performance of the valve trims experimental tests have been conducted. The effect of both the manufacturing methods on the local performance of the valve trims has been investigated using CFD simulations.

\section{Details of SLM manufacturing process employed}

The design of the trim used in this study is quite complex where the fluid flows on welldesigned flow paths on discs that are arranged in a stack. A single disc of the trims is shown in Fig. 2 (a). As can be seen in the figure, there are five rows of cylinders of varying diameters on the disc. If the EDM method is used to manufacture such trims, each disc needs to be manufactured separately and then arranged in a stack and welded together whereas using the SLM method the whole trim can be manufactured additively. Manufacturing the trim using SLM also reduced the manufacturing cost by 50\%. Figs. 2(b) and 2(c) show the trims manufactured using the EDM and SLM methods respectively. A Renishaw AM250 machine was used to manufacture the SLM trim. The process parameters for the SLM manufactured trim are shown in Table 1. It can be seen from the table that the trim was manufactured in 16 hours which is significantly less time as compared to trims manufactured by EDM (up to ten weeks). The hatch spacing of $13 \mu \mathrm{m}$ is close to the range of hatch spacing suggested by Enneti et al.[7] who reported that high density parts can be manufactured using smaller hatch spacing. It can be seen from the table that the trim has been manufactured to a density of $99.8 \%$. Note that the density of the part has been reported in percentage here because it is the density of the part relative to the particle density of the material.

\begin{tabular}{ll}
\hline Density & $99.80 \%$ \\
Layer thickness $(\mu \mathrm{m})$ & 50 \\
Feature size $(\mu \mathrm{m})$ & 200 \\
Laser spot size $(\mu \mathrm{m})$ & 100 \\
Hatch distance $(\mu \mathrm{m})$ & 13 \\
Point distance $(\mu \mathrm{m})$ & 50 \\
Laser power $(\mathrm{W})$ & 120 \\
Exposure time $(\mu \mathrm{s})$ & 220 \\
Overall production & 16 \\
time (hours) & \\
\hline
\end{tabular}

Table 1. Process parameters for SLM [1] 


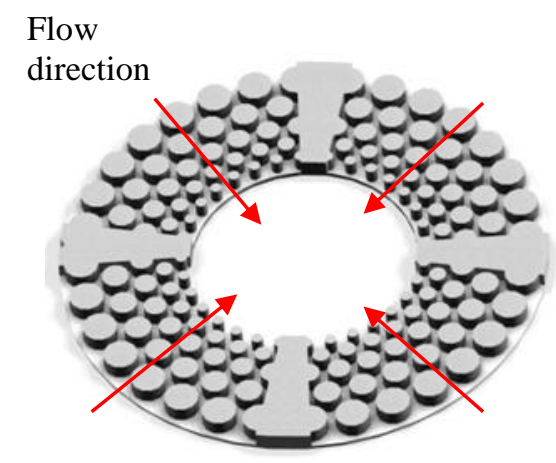

(a) Single disc of the full column trim

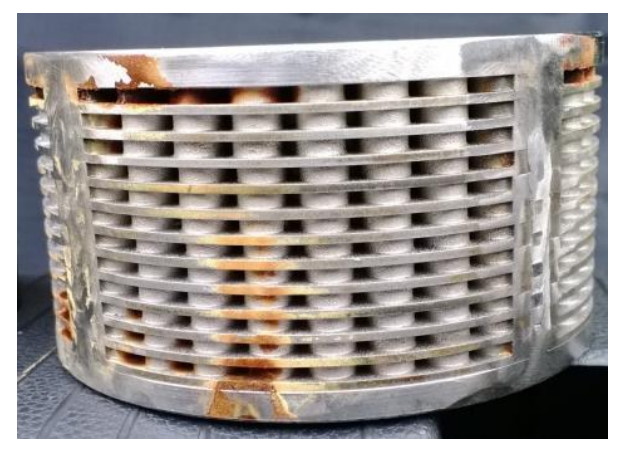

(b) EDM trim

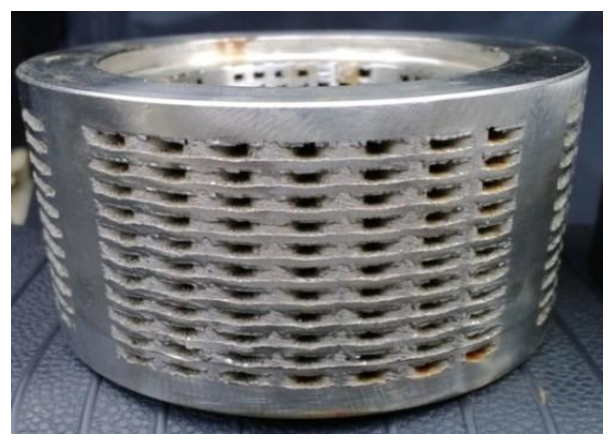

(c) SLM trim

Fig. 2. EDM and SLM manufactured valve trims

\section{Flow coefficient of the valve trim}

The flow coefficient of a valve, $\mathrm{C}_{\mathrm{L}}$, is one of the most important parameters that can be used to evaluate the valve hydraulic performance. $\mathrm{C}_{\mathrm{L}}$ is a function of the volumetric flow rate $(\mathrm{Q})$ and the pressure drop $(\Delta p)$ across the valve, and the surface finish of the valve is one of the parameters that may affect it. The valve flow coefficient can be determined using Eqn. 1[21]:

$$
Q=N_{1} F_{R} F_{P} C_{L_{\text {valve }}} \sqrt{\frac{\Delta p}{\rho / \rho_{o}}}
$$

where, $N_{1}$ is a numerical constant that depends on the units used, $F_{R}$ is the Reynolds number factor, $F_{P}$ is the piping geometry factor, $\mathrm{C}_{\text {Lvalve }}$ is the flow coefficient of the valve in US gallons $\min ^{-1} \mathrm{psi}^{-1 / 2}$ and $\rho / \rho_{o}$ is the relative density. If the units used for volumetric flow rate and differential pressure are $\mathrm{m}^{3} / \mathrm{h}$ and $\mathrm{kPa}$ respectively, the value of $N_{1}$ is 0.0865 . For turbulent flows, $F_{R}=1 . F_{P}=1$, if no fittings (reducer, expander, etc.) are attached to the piping. For water, $\rho / \rho_{o}=1$. Thus, Eq. 1 can be written as:

$$
C_{L_{\text {valve }}}=\frac{Q}{0.0865} \sqrt{\frac{1}{\Delta p}}
$$


The valve is composed of the trim, the valve body and the seat, therefore, the overall $\Delta p$ across the valve is the sum of pressure drops across each of these:

$$
\Delta p=\Delta p_{\text {valve body }}+\Delta p_{\text {trim }}+\Delta p_{\text {seat }}
$$

As it can be seen from Eq. 2 that the pressure drop is inversely proportional to the square of the flow coefficient, therefore:

$$
\frac{1}{C_{L_{\text {valve }}}{ }^{2}}=\frac{1}{C_{L_{\text {valve body }}}{ }^{2}}+\frac{1}{C_{L_{\text {trim }}}{ }^{2}}+\frac{1}{C_{L_{\text {seat }}}{ }^{2}}
$$

The flow coefficients of the valve body $\left(\mathrm{C}_{\mathrm{Lvalve}}\right.$ body $)$ and the seat $\left(\mathrm{C}_{\mathrm{Lseat}}\right)$ can be calculated as:

and,

$$
C_{L_{\text {valve body }}}=k_{1}\left(\frac{D_{\text {Valve }}}{D_{\text {Seat }}}\right)^{2}
$$

$$
C_{L_{\text {seat }}}=k_{2}\left(\frac{D_{\text {Valve }}}{D_{\text {Seat }}}\right)^{2}
$$

where, $k_{1}$ and $k_{2}$ are geometry dependent coefficients of the valve and the seat, and $D_{V a l v e}$ and $D_{\text {Seat }}$ are the diameters of the valve and seat respectively. Here, the values of $C_{L}$ for the valve body and the seat are 301.6 and 65 respectively [16].

Therefore, to determine the $C v$ value for the trim, Eq. 4 can be transformed into:

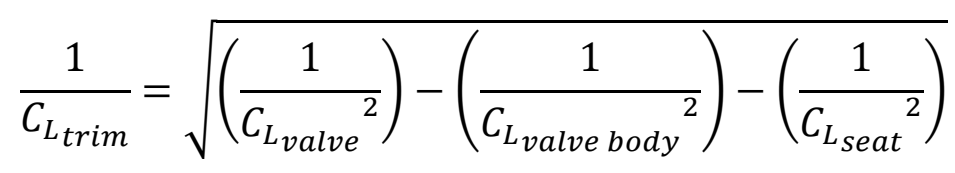

The trim geometry is designed according to the required $\mathrm{C}_{\mathrm{Ltrim}}$ which is defined by the process requirements. Therefore, for performance comparison of EDM and SLM trims, experiments have been conducted to determine the $\mathrm{C}_{\text {Lvalve }}$. By using the values of the valve body and seat flow coefficients given above, $\mathrm{C}_{\text {Ltrim }}$ can be calculated using Eqn. 7 .

\section{Experimental set-up}

The flow loop for testing the capacity of the valve trims has been set up according to standard BS EN 60534-2-3 [21], and test procedure VT-QC-SP503 [22]. The valve used in this study is a globe valve with inlet and outlet diameter of $100 \mathrm{~mm}$. The valve is attached to a pipe of nominal diameter $100 \mathrm{~mm}$ in the arrangement shown in Fig. 3. The length of the upstream pipe is $2 \mathrm{~m}$ while the downstream pipe is $1.8 \mathrm{~m}$ long. Inlet pressure at the valve is measured at pressure taps installed at a distance of $200 \mathrm{~mm}$ upstream of the valve while the outlet pressure is measured at pressure taps installed $600 \mathrm{~mm}$ downstream of the valve. There are four pressure taps at the upstream and downstream locations which are installed circumferentially and spaced equally at both locations. At these locations, average pressure is measured by the pressure transducers. Water is circulated through the flow loop by a centrifugal pump. The flow rate is measured using a turbine flow meter. The data from the turbine flow meter and the pressure transducers is collected via Omega USB-4718 data acquisition module. The temperature of the test fluid is measured using a thermocouple which is installed within the water storage tank. Fig. 4 shows the pneumatically actuated control 
valve along with the location of pressure taps. The actuator is connected to an air supply at 4 bar (g). The VOP is controlled by adjusting the air supply pressure.

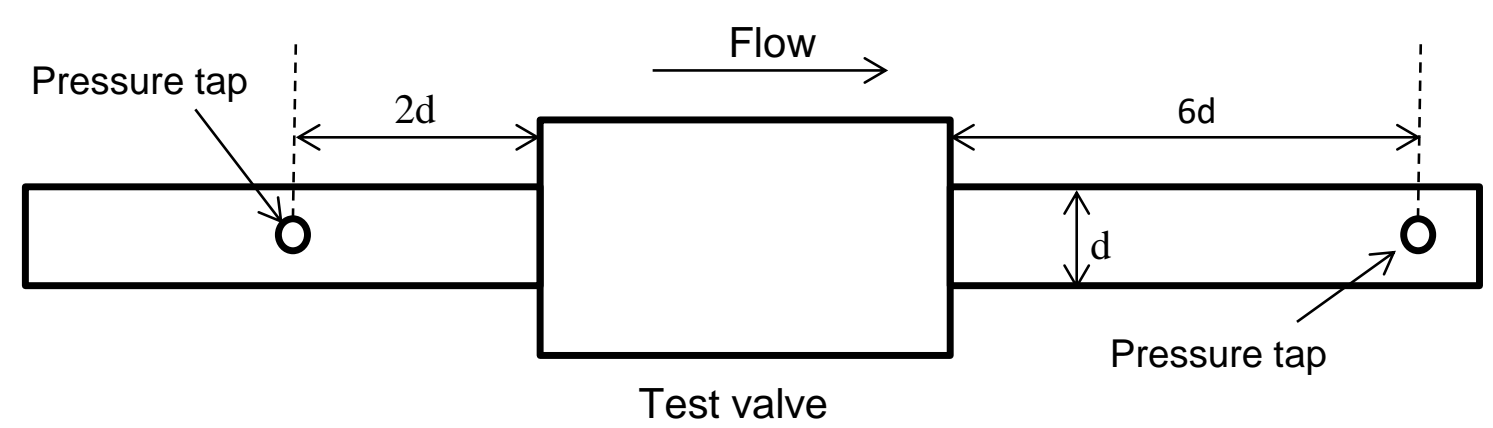

Fig. 3. Schematic of the test section and position of pressure taps

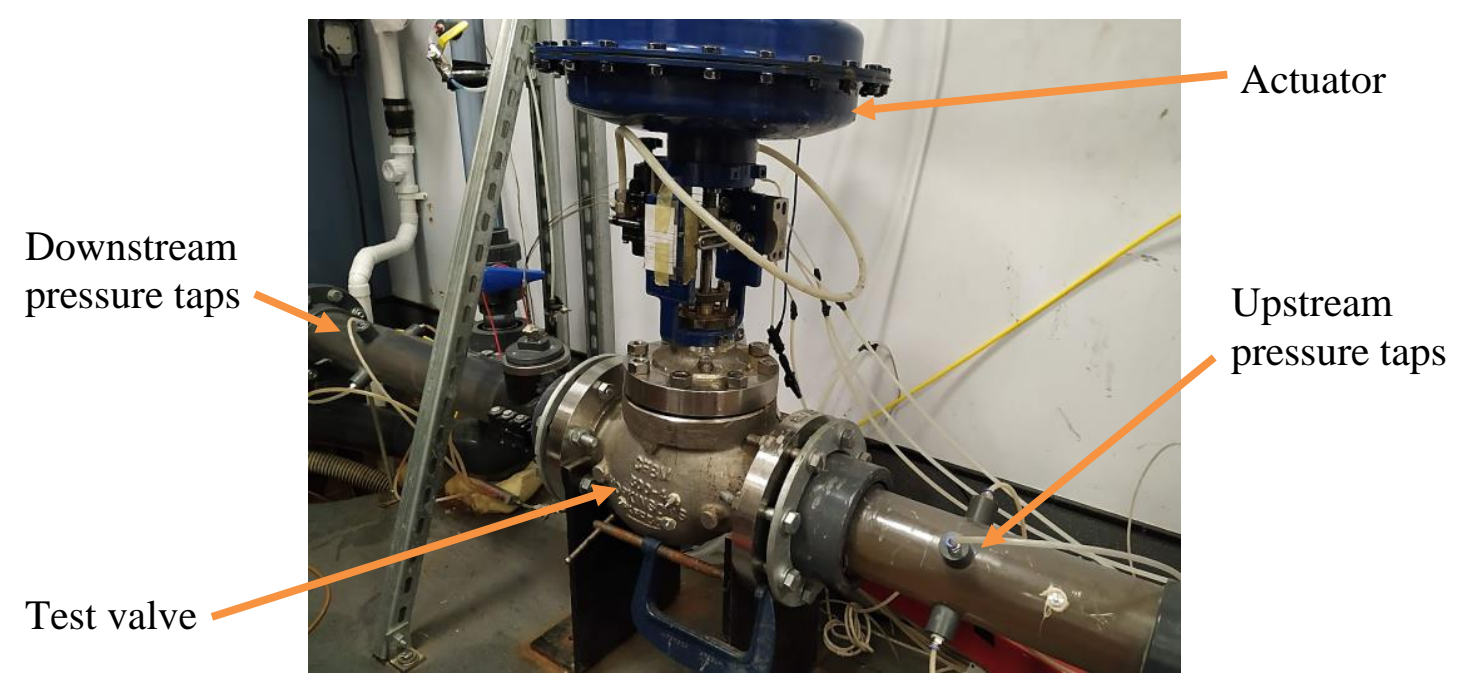

Fig. 4. Test valve set-up

In order to cover the normal operating of the valve, experimental testing was conducted at a range of flow rates and various VOPs. At each test condition, the inlet absolute pressure, pressure differential across the valve, inlet water temperature, volumetric flow rate and barometric pressure were recorded. The pressure sensors had an accuracy of $\pm 2.5 \mathrm{kPa}$ and the accuracy of the flow meter was $\pm 2 \mathrm{~m}^{3} / \mathrm{hr}$. Every measurement was recorded five times and averaged. The experimental results reported in the next section are the averaged measurements of pressure drop and flow rates. The standard deviations of the repeated measurements of pressure drops and flow rates at each test condition were within $2.7 \%$ and $9.4 \%$ of the mean values respectively.

\section{Experimental results}

Fig. 5 shows the variation of pressure drop against flow rate for different valve opening positions for the EDM trim. It can be seen that the pressure drop increases with the flow rate for each valve opening position. For lower VOPs (10\% and 20\%), the pressure drop increases rapidly as compared to higher flow rates. This indicates that the flow resistance is higher 
(slope of the curve) for lower VOPs as compared to higher VOPs. This observation is in agreement with that reported by Asim et al $[16,17]$.

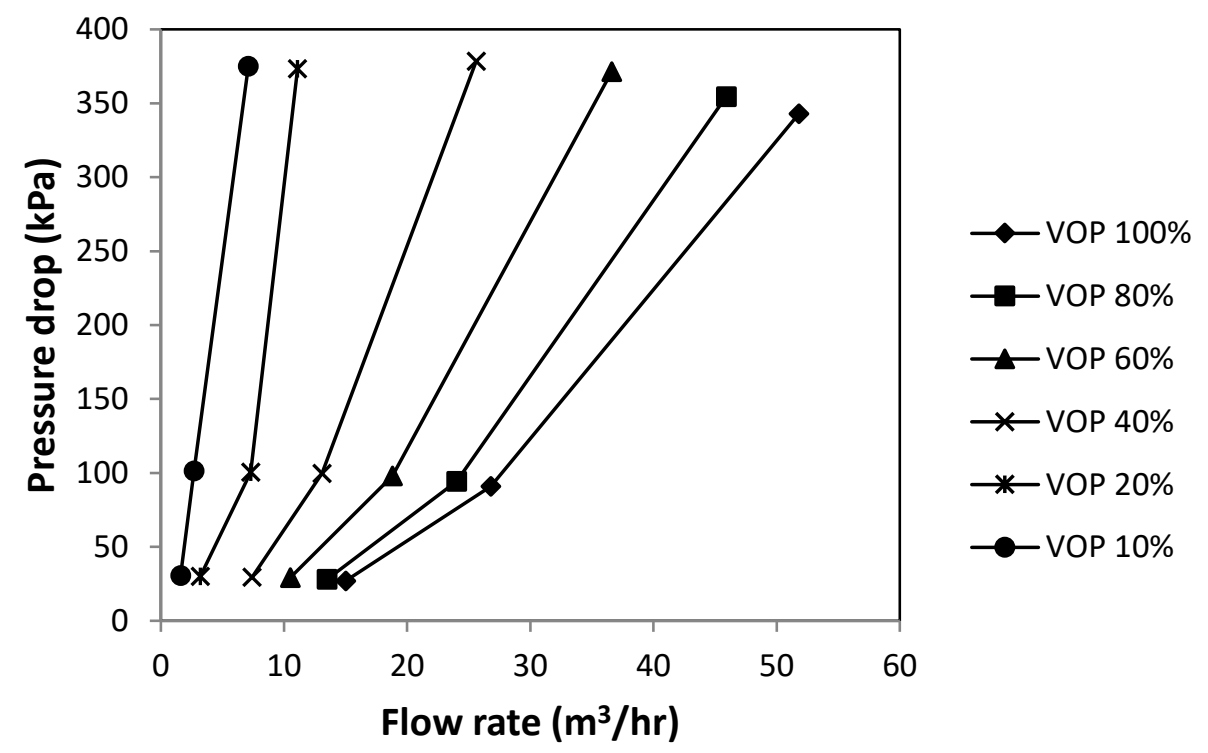

Fig. 5. Pressure drop vs flow rate different valve opening positions for the EDM trim

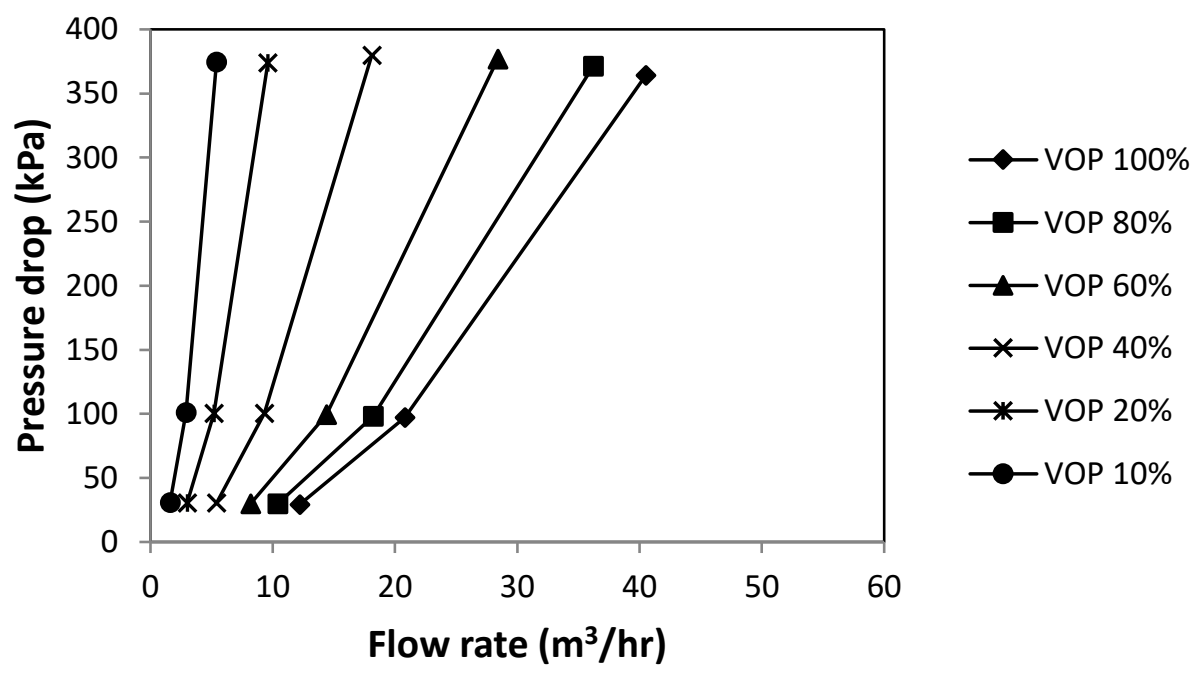

Fig. 6. Pressure drop vs flow rate different valve opening positions for the SLM trim

Fig. 6 shows the variation of pressure drop against flow rate for different valve opening positions for the SLM trim. As can be seen from the figure, the results for this trim also show similar trends in the variation of volumetric flow rate and pressure drop at different VOPs as the EDM trim. However, the SLM trim encounters higher pressure drop per unit flow rate as compared to the EDM trim, as indicated by the higher slopes of the line corresponding to each valve opening. Thus, the SLM trim is associated with higher flow losses as compared to the EDM trim. This aspect has been explained in more details through the use of valve coefficient in Figs. 7 and 8.

Fig. 7 shows the variation of $\mathrm{C}_{\text {Ltrim }}$ (calculated using Eq. 7) with flow rate at different VOPs for the EDM trim. At each VOP, three $\mathrm{C}_{\text {Ltrim }}$ values have been computed corresponding to the 
three flow rates and pressure drops that were shown in Fig. 5. It can be seen from the figure that $\mathrm{C}_{\text {Ltrim }}$ remains nearly constant for each valve opening position. This is expected because $\mathrm{C}_{\mathrm{Ltrim}}$ is dependent on the VOP, and not the flow conditions. These results are consistent with the findings of Asim et al $[15,16]$ and Oliveira [18]. It can also be seen from the figure that $\mathrm{C}_{\mathrm{Ltrim}}$ increases linearly with increase in VOP. Fig. 8 shows the variation of $\mathrm{C}_{\mathrm{Ltrim}}$ with flow rate at various VOPs for the SLM trim. Again, it can be seen from the figure that $\mathrm{C}_{\mathrm{Ltrim}}$ remains nearly constant for each VOP and increases linearly with increase in VOP, similar to the EDM trim. At $100 \%$ VOP, the average value of $\mathrm{C}_{\text {Ltrim }}$ for the EDM trim is 37.52 while it is 26.58 for the SLM trim, which is a $29 \%$ drop in the performance.

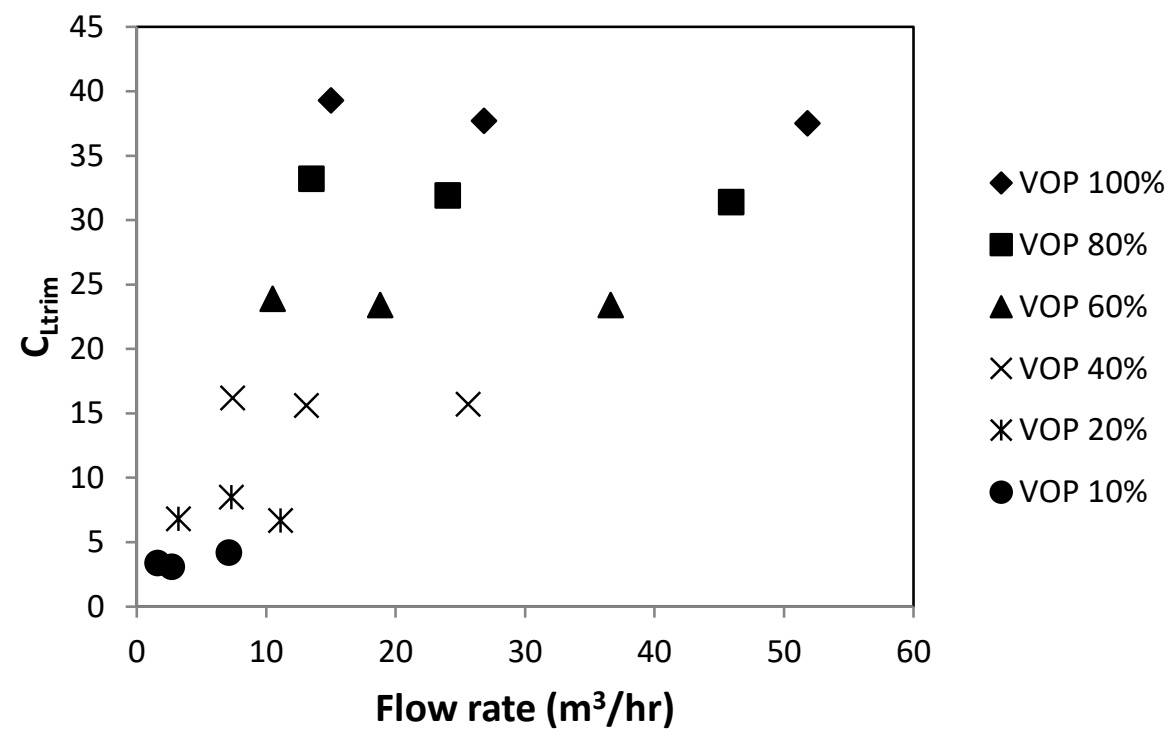

Fig. 7. Variation of $C_{\text {Ltrim }}$ with flow rate at various valve opening positions - EDM trim

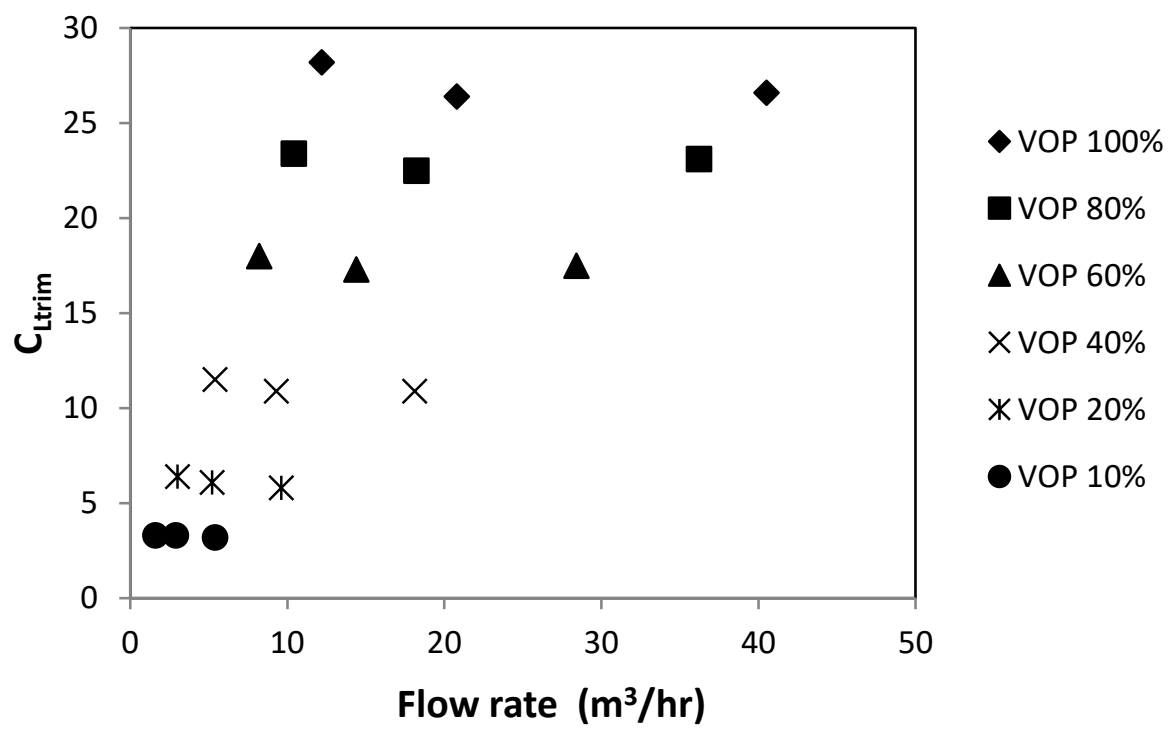

Fig. 8. Variation of $C_{\text {Ltrim }}$ with flow rate at various valve opening positions - SLM trim 
In order to visualise the loss in flow performance between the trims manufactured using the two different manufacturing methods, the ratios of $C_{\text {Ltrim }}$ between SLM and EDM trims have been plotted in Fig. 9. It can be seen that the flow coefficient ratio decreases drastically from 0.91 to 0.7 with a linear trend from $10 \%$ to $40 \%$ valve opening position. At valve opening positions higher than $40 \%$, the ratio of flow coefficients is nearly constant and in the range of $0.7-0.74$.

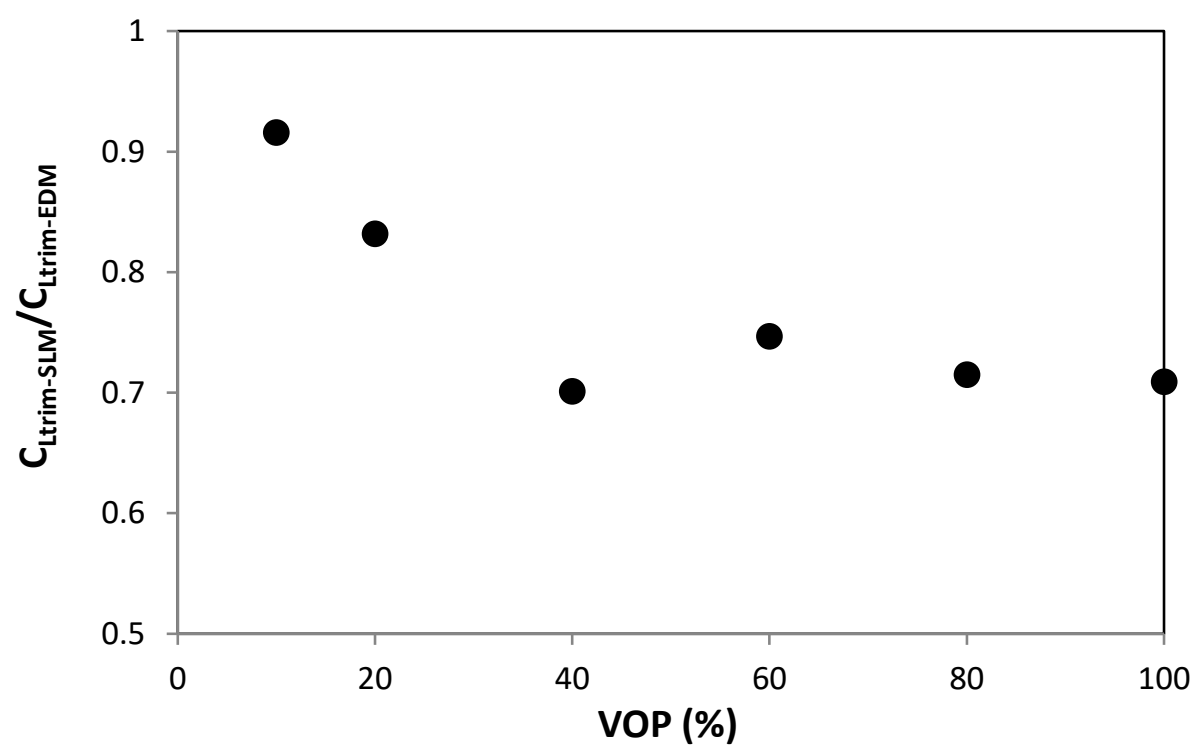

Figure 9. Ratios of flow coefficients of SLM to EDM trims at various valve opening positions

The reason for the decrease in the flow capacity of the SLM trim is the likely difference in surface topography of these parts as well as geometrical imperfections created which is a direct outcome of manufacturing process parameters. In order to compare the surface topography of these parts, areal surface roughness measurements were carried out at various sections of the trims using Focus Variation Microscopy (Alicona G4, Austria). It has been shown that this methodology has an excellent capacity to record the topography of SLM surfaces [23]. Note, the measurements were not filtered after measurement as would be standard practice to quote ISO 25178 compliant results. Non filtered surface map data was considered more suitable for use in the models as longer wavelength components of the real measured surface would be not be filtered out. It was found that the mean of the roughness Sa of the EDM trim was $9.2 \mu \mathrm{m}$ whereas the mean of the roughness Sa of the SLM trim was found to be $37.7 \mu \mathrm{m}$ which is approximately 4 times higher. The developed surface area ratio parameter, $\mathrm{Sdr}$, records the ratio of the projected area of the surface area to the real measured surface area, where the results are expressed as a \%. In the case here, the average Sdr of the EDM trims was $82.3 \%$ and the SLM trims was $229 \%$ (2.8 times of EDM). The Sa parameter shows that the SLM surface has greater amplitude of roughness than the EDM surface. In addition, the Sdr value reflects the highly re-entrant nature of the SLM surface. This scale of roughness may be a major factor in the reduction of the capacity of these trims as it offers an increased resistance to the flow [13]. This means that for the SLM trims, the surface area in contact with the fluid is higher which results in greater resistance to the flow, and hence, a reduction in $\mathrm{C}_{\mathrm{L}}$. The surface maps for the two trims are shown in Fig.10.

Valve capacity is one of the most important factors to be considered in valve design by the valve companies. The global flow capacity through valve is reduced by manufacturing the trim by the SLM method, however, the SLM method showed a $50 \%$ reduction in costs of 
manufacture and significant reduction in manufacturing lead time. The estimation of effects of local roughness variations on flow performance using experimental means is very difficult hence the possibility of using a well validated numerical scheme for this purpose has been explored in the next section.

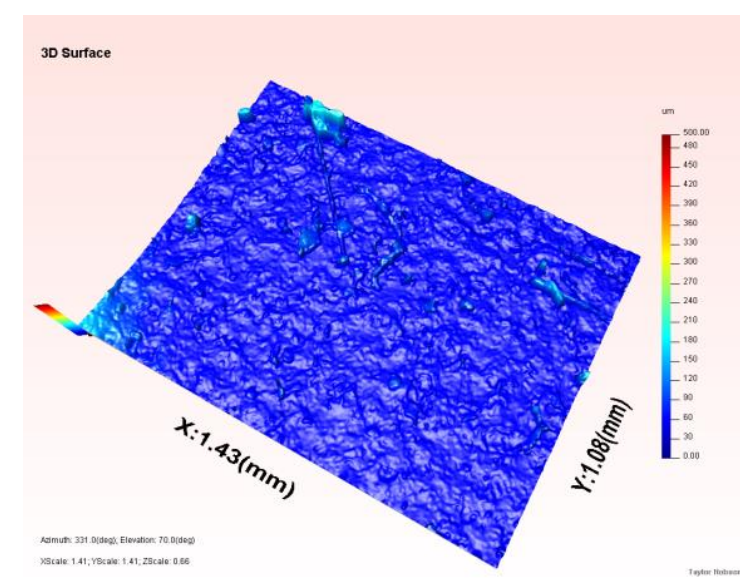

(a)

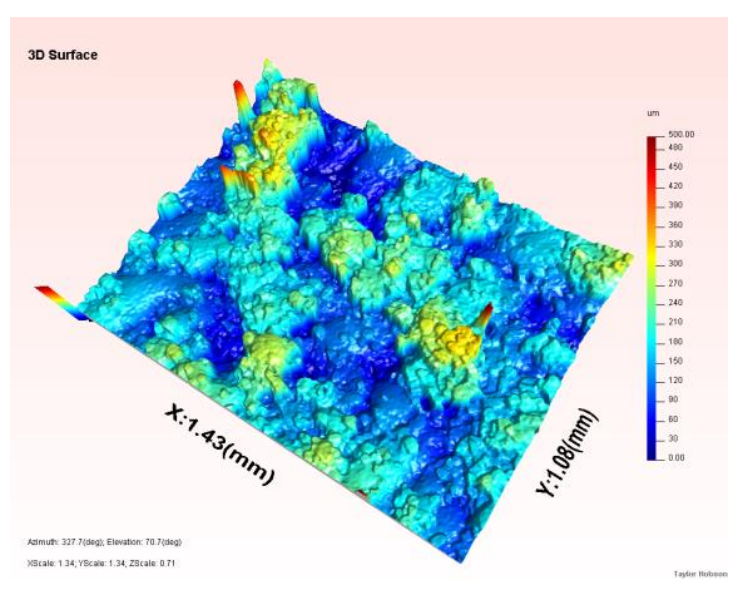

(b)

Figure 10. Areal surface maps of a) EDM surface b) SLM surface, maps plotted on same scale

\section{CFD modelling of the control valve}

In the previous section, the global flow parameters of the valves manufactured by both the manufacturing methods have been determined by experimental methods. The experimental methods currently can only provide information on the global performance parameters and have severe limitations in providing local flow field information. During the operation of valves, various problems such as cavitation and erosion can develop, which are local phenomena and therefore, it is important to investigate the local flow parameters of the valves which could be utilised to optimise the performance characteristics of the valve trims. The investigation of local flow parameters can also provide detailed information on how the change in the surface finish affects the flow field within the discs of the valve trim locally which affects the overall $\mathrm{C}_{\mathrm{L}}$. Therefore, in order to evaluate the effect of the manufacturing method on the local performance of the valve trims, numerical simulations have been conducted. The three-dimensional model of the valve trim used in these simulations is shown in Fig. 11. There are 11 discs in the trim stack and the flow direction within the discs is from the outer diameter towards the inner diameter, i.e., from row 1 to row 5 as shown in Fig. 11(a). Each disc is made up of four identical quarters. In each quarter, there are different flow paths in between the cylinders where fluid can flow. There are 7 flow paths on rows 1, 3 and 5 whereas there are 8 flow paths on rows 2 and 4 as shown in Fig. 11(b). 


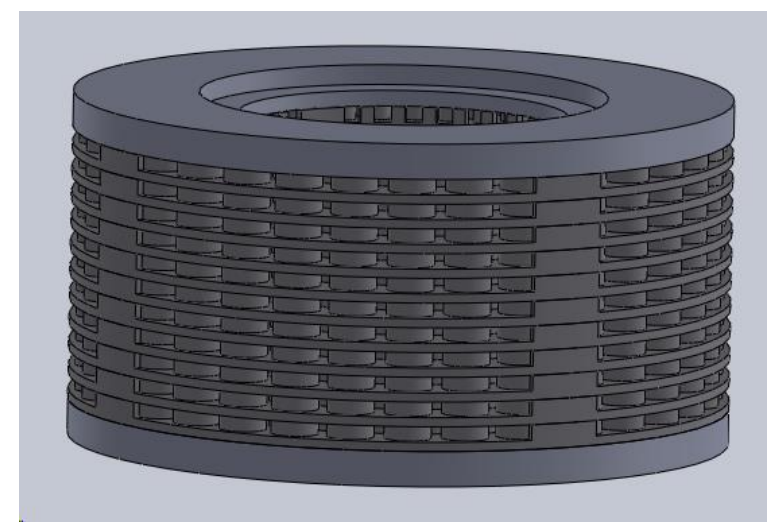

(a)

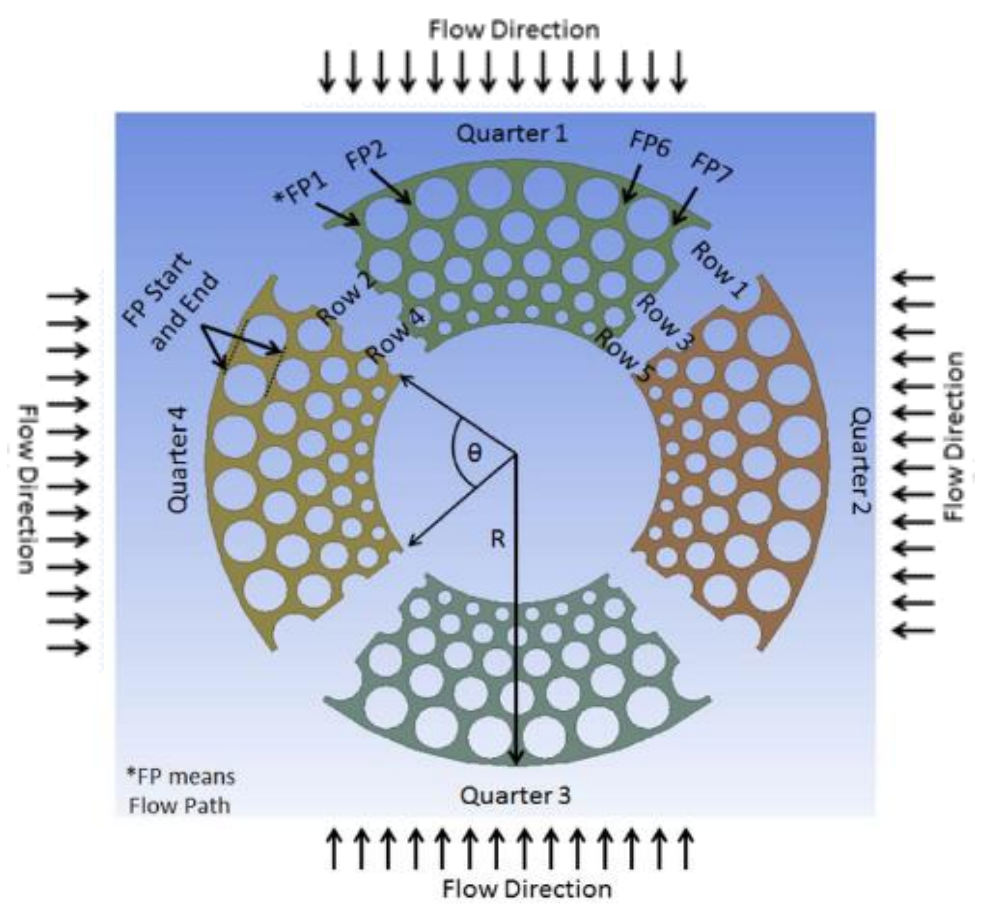

(b)

Fig. 11. (a) 3-D model of the trim (b) Single disc of the valve trim showing flow paths

The inlet and the outlet boundary conditions were specified according to the experimental flow rates and outlet pressure at the pressure tapping locations. Therefore, pipe sections of length $2 \mathrm{D}$ and $6 \mathrm{D}$ were added at the valve inlet and the outlet respectively, according to industry standards. The pipe sections were meshed using hexahedral elements where the geometry is relatively simple, whereas the valve body and the trim were meshed using tetrahedral elements where the geometry is highly complex. The element size in the pipe sections was $3 \mathrm{~mm}$ and the valve body and valve trim had a minimum element sizing of 0.35 $\mathrm{mm}$ and a maximum element size of $3 \mathrm{~mm}$ resulting in 5.3 million mesh elements in the flow domain. Fig. 12 shows the mesh generated for the flow domain. The suitability of the mesh sizing for this particular type of valve has been shown by Asim et al. in their previous studies $[16,17]$. They conducted mesh independence study for four different mesh configurations for this valve: 3.4 million, 4.3 million, 5.3 million and 6.5 million mesh elements. It was found that the inlet pressure increased by $5 \%$ if the mesh elements were increased from 3.4 million to 4.3 million. Using 5.3 million elements, the inlet pressure further increased by $1.9 \%$ while 
increasing the mesh elements to 6.5 million, the inlet pressure decreased by $0.9 \%$. The mesh with 5.3 million elements was chosen because the difference in the inlet pressure was less than $1 \%$ as compared to the mesh with 6.5 million elements [16,17]. ANSYS Fluent 17.0 has been used to conduct the numerical flow simulations. The turbulence model employed is a two equation Shear Stress Transport (SST) k- $\omega$ model because it has been shown to be effective in modelling the severe velocity gradients accurately in control valve applications [24-27].

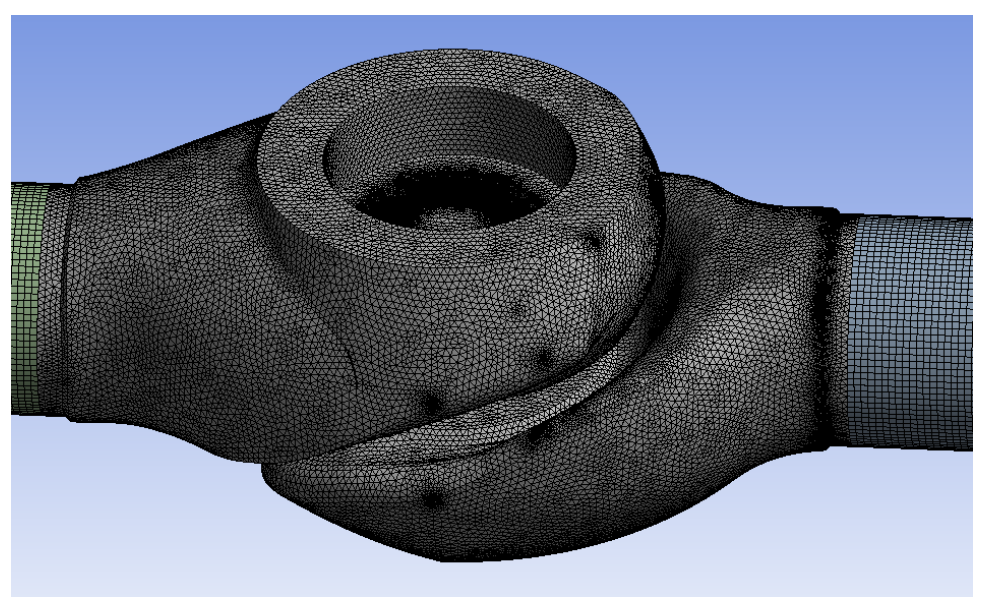

(a)

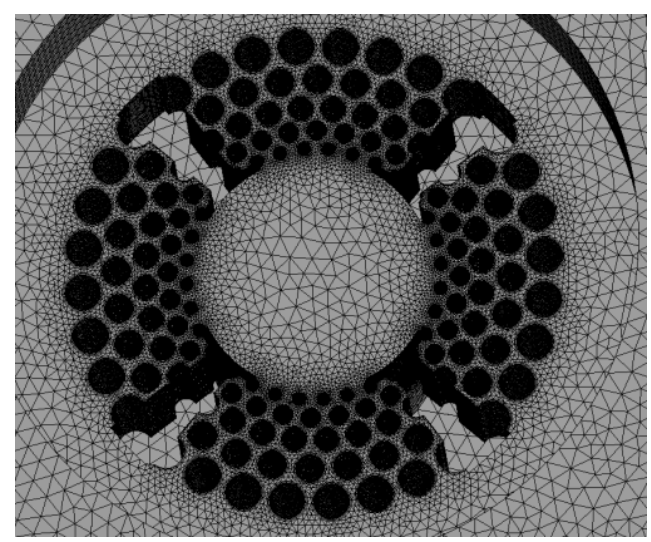

(b)

Fig. 12. Mesh in (a) the valve (b) the trim

The effect of the surface roughness of the trims was modelled by using the modified law-ofthe-wall for roughness [28] which is defined as:

$$
\frac{u_{p} u^{*}}{\tau_{w} / \rho}=\frac{1}{K} \ln \left(E \frac{\rho u^{*} y_{p}}{\mu}\right)-\Delta B
$$

where, $u_{p}$ is the fluid mean velocity at the wall-adjacent cell centroid, $u^{*}$ is the friction velocity, $y_{p}$ is the distance from the wall to the wall-adjacent cell centroid, $\tau_{w}$ is the wall shear stress, $K=0.4187$ is the von Karman constant, $E=9.793$ is an empirical constant and $\mu$ 
is the dynamic viscosity of the fluid. The friction velocity is related to a constant $C_{\mu}$ and the turbulent kinetic energy $(k)$ by the following equation:

$$
u^{*}=C_{\mu}^{0.25} k^{0.5}
$$

$\Delta B$ is related to $K_{S}^{+}$(non-dimensional roughness height) which is defined as:

$$
K_{s}^{+}=\frac{\rho K_{s} u^{*}}{\mu}
$$

where, $K_{S}$ is the physical roughness value.

For hydrodynamically smooth regime $\left(K_{S}^{+} \leq 2.25\right)$ :

$$
\Delta B=0
$$

For the transitional regime $\left(2.25 \leq K_{s}^{+} \leq 90\right)$ :

$$
\Delta B=\frac{1}{K} \ln \left[\frac{K_{s}^{+}-2.25}{87.75}+C_{s} K_{s}^{+}\right] \times \sin \left[0.4258\left(\ln K_{s}^{+}-0.811\right)\right]
$$

where, $C_{s}$ is a roughness constant which depends on the type of roughness.

In the fully rough regime $\left(K_{S}^{+}>90\right)$ :

$$
\Delta B=\frac{1}{K} \ln \left(1+C_{s} K_{s}^{+}\right)
$$

In the simulations conducted for this paper, a roughness height $\left(K_{S}\right)$ of 500 microns and 1000 microns was specified for the EDM and SLM trims respectively. These $K_{S}$ values have been chosen to match the global $\mathrm{C}_{\mathrm{L}}$ results with experiments and to take into account that several flow paths that were found to be completely blocked on the SLM trim. The roughness constant $\left(C_{s}\right)$ was specified as 1 to represent the non-uniform roughness.

In order to determine the accuracy of the numerical modelling, CFD results have been verified against the experimental results by comparing the $\mathrm{C}_{\text {Ltrim }}$ values as shown in Table 2 . The simulations for both trims were run at $100 \%$ VOP. It can be seen in the table that there is a difference of only $3.27 \%$ and $1.8 \%$ in the $C_{\text {Ltrim values for the EDM and SLM trims }}$ respectively. Therefore, the CFD results show a close agreement with the experimental results.

\begin{tabular}{llll}
\hline Trim & $\begin{array}{l}\text { Experimental } \\
\text { CLtrim }\end{array}$ & $\begin{array}{l}\text { CFD predicted } \\
\text { CLtrim }\end{array}$ & \% Difference \\
\hline EDM & 37.52 & 36.29 & -3.27 \\
SLM & 26.58 & 27.06 & +1.8 \\
\hline
\end{tabular}

Table 2. Verification of CFD results 


\section{Local performance analysis of the EDM and SLM trims}

In order to compare the performance of the two trims on the local level, a detailed investigation was conducted on local flow coefficients within the trims at different flow paths within different rows of cylinders on the discs as well as the variation of pressure and velocity within the top disc in the trims at the $100 \%$ valve opening position. This analysis is shown on a quarter of the disc as the other quarters exhibit similar behaviour.

\subsection{Local flow coefficients}

In order to evaluate the difference in performance of the valve trims at local level, flow capacities were calculated at all the flow paths on a quarter of the top disc of the valve trims. The local flow coefficient of a flow path was calculated using the pressure drop and the flow rate across each flow path using Eqn. 2. Fig. 13 shows the location of these flow paths on a quarter of the trim disc. As can be seen from the figure, there are seven flow paths in rows 1 , 3 and 5 whereas there are eight flow paths. The start and end of each flow path is considered to be at the entry and exit of each row of cylinders. Table 3 shows normalised local flow coefficients of all flow paths at each row of cylinders on the EDM trim while Table 4 shows normalised local flow coefficients of all flow paths of the SLM trim. The coefficients have been normalised by the average of flow path flow coefficients for each row. The tables show that the normalised local flow coefficients remain nearly constant (close to 1) at different flow paths of first, third and fifth rows because the all the flow paths are similar. At second and fourth rows, the normalised local flow coefficients are nearly 0.5 in flow paths 1 and 8 whereas they are in the range of 1.1-1.2 in flow paths 2-7. This is because of the difference in the geometry of flow paths 1 and 2 as compared to other flow paths in rows 2 and 4.

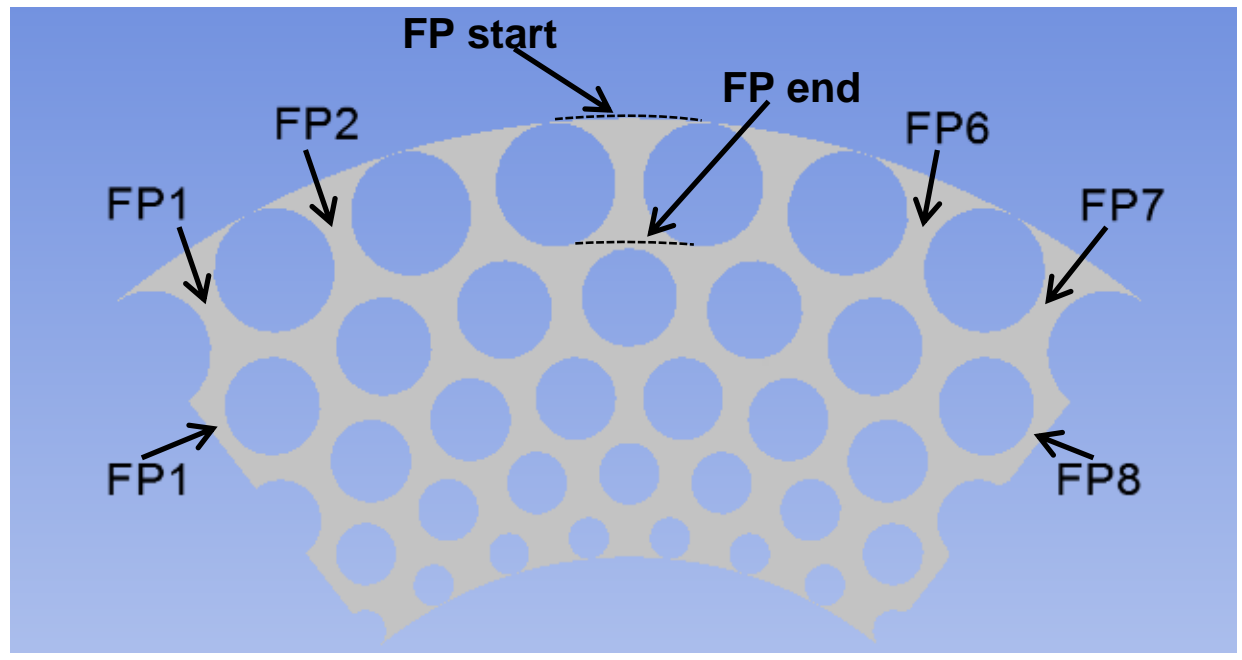

Fig. 13. Flow paths between cylinders on a quarter of the trim disc (FP = flow path)

It can be seen from Table 3 that, for the EDM trim, the highest flow coefficient is observed to at row 5 while row 3 has the lowest flow coefficient. In the direction of flow, there is a reduction of $8 \%$ in the average local flow coefficient from row 1 to 2 , a reduction of $2 \%$ 
from row 2 to 3 whereas it increases by $2.8 \%$ from row 3 to 4 and by $36.5 \%$ from row 4 to 5. From Table 4, it can be seen that for the SLM trim, the highest flow coefficient is still observed at row 5 but the lowest flow coefficient is seen at row 4 . The normalised local flow coefficient in the SLM trim decreases from row 1 to 2 by $8.7 \%$, from row 2 to 3 by $2.5 \%$, from row 3 to 4 by $1.9 \%$ whereas it increases from row 4 to 5 by $3.3 \%$.

\begin{tabular}{lrrrrr}
\hline Flow & \multicolumn{5}{c}{ C $_{\mathrm{L} \text { Flow path / Average C } \mathrm{L}-\text { Row }}$} \\
\cline { 2 - 6 } path & Row 1 & Row 2 & Row 3 & Row 4 & Row 5 \\
\hline 1 & 1.007 & 0.502 & 1.004 & 0.514 & 1.006 \\
2 & 1.007 & 1.174 & 1.008 & 1.192 & 1.003 \\
3 & 0.985 & 1.178 & 1.004 & 1.137 & 0.994 \\
4 & 0.993 & 1.190 & 0.992 & 1.176 & 0.989 \\
5 & 1.018 & 1.126 & 0.984 & 1.137 & 0.971 \\
6 & 1.011 & 1.134 & 0.984 & 1.161 & 0.994 \\
7 & 0.989 & 1.166 & 1.012 & 1.141 & 1.049 \\
8 & & 0.514 & & 0.545 & \\
\hline Average & 0.275 & 0.253 & 0.248 & 0.255 & 0.348 \\
CL-Row & & & & & \\
\hline
\end{tabular}

Table 3. Local flow coefficients of different flow paths of a quarter of the top disc of the EDM trim

\begin{tabular}{llllll}
\hline Flow & \multicolumn{5}{c}{ C $_{\text {L-Flow path/Average } C_{L-R o w}}$} \\
\cline { 2 - 6 } path & Row 1 & Row 2 & Row 3 & Row 4 & Row 5 \\
\hline 1 & 0.997 & 0.506 & 1.006 & 0.521 & 1.020 \\
2 & 0.993 & 1.153 & 1.000 & 1.162 & 0.996 \\
3 & 1.001 & 1.167 & 1.001 & 1.172 & 0.989 \\
4 & 1.008 & 1.175 & 0.999 & 1.160 & 0.987 \\
5 & 1.001 & 1.162 & 0.986 & 1.146 & 0.988 \\
6 & 0.994 & 1.164 & 0.997 & 1.151 & 0.993 \\
7 & 1.006 & 1.160 & 1.009 & 1.160 & 1.027 \\
8 & & 0.512 & & 0.528 & \\
\hline $\begin{array}{l}\text { Average } \\
\text { CL-Row }\end{array}$ & 0.267 & 0.244 & 0.237 & 0.233 & 0.311 \\
\hline
\end{tabular}

Table 4. Local flow coefficients of different flow paths of a quarter of the top disc of the SLM trim

Comparing the local flow coefficients of the rows in both the trims shows that the local flow coefficients of all the rows are lower in the SLM trim. The decrease in the flow coefficient in the SLM trim for rows 1 to 5 is $3 \%, 3.7 \%, 4.2 \%, 8.6 \%$ and $10.6 \%$ respectively. The decrease in the flow capacity of each row contributes to the overall drop in $\mathrm{C}_{\mathrm{L}}$ for the trim manufactured by the SLM method. The decrease in the flow coefficients is depicted in the form of ratios of the flow capacities of SLM and EDM across different rows in Fig. 14. In this graph, the ratio of flow coefficients ratio is plotted against $A_{\text {in }} / A_{\text {out, }}$, where $A_{\text {in }}$ is the area at the inlet and $A_{\text {out }}$ is the area at the outlet of the flow paths at each row. The graph shows that decrease in the flow coefficient ratios increase with increase in $A_{\text {in }} / A_{\text {out. }}$. The flow coefficient ratio is highest in row 1 and minimum in row 5. 


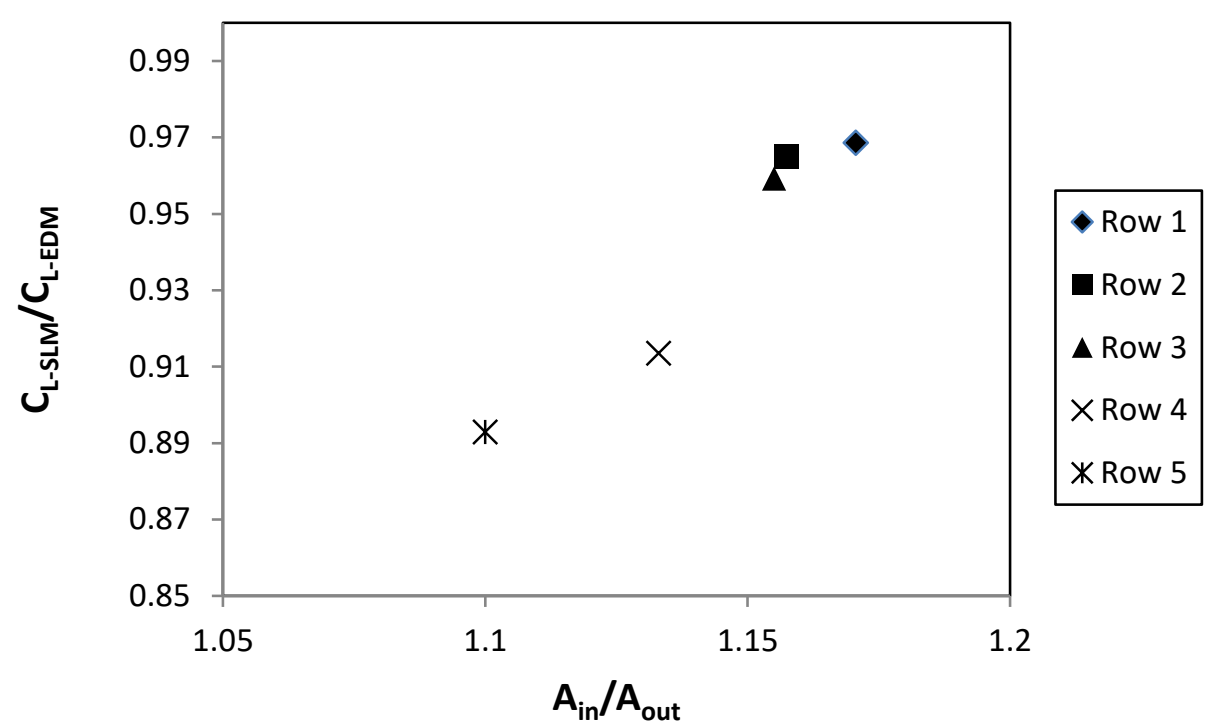

Fig. 14. Ratio of local flow capacities of SLM and EDM trims across different rows

In order to investigate the reasons that contribute to the difference in the flow capacities of both the trims, the analysis of the local pressure and velocity variations within the top disc of the trim is presented in the following sections.

\subsection{Pressure variations}

In order to visualise the pressure variations within the trims, static gauge pressure contours at the top disc of both the trims are shown in Fig. 15. The pressure contours of the EDM trim are consistent with the contours obtained by Asim et. al [16]. The figure shows high pressure at the trim entrance. After entering the first row, the flow area in the flow path reduces and thus, the static pressure decreases. The flow area increases afterwards in the second half of the flow path and the static pressure rises consequently. The same phenomenon is repeated when the flow passes through each row of cylinders. From the pressure contours for both the trims, it can be seen that there is higher pressure drop across each row of cylinders in the SLM trim as compared to the EDM trim.

The pressure variations within the trim were further analysed along the central flow route shown in Fig. 15(a). Fig. 16 shows the static pressure variation on both the trims at the central flow route which has been normalised with the static pressure of water at the inlet of the trim. The $\mathrm{x}$-axis shows the normalised radial co-ordinates where, $\mathrm{R}$ is the external radius of the trim and $\mathrm{r}$ is the corresponding radial co-ordinate of the point on the central flow route. The pairs of dotted vertical lines represent the area between each subsequent row. Again, this graph shows the aforementioned phenomenon of pressure drop and pressure recovery as the flow passes through the flow paths between the rows. It can be seen from the graph that at the row 1 exit, the normalised static pressure drops to 0.91 in the EDM trim whereas it drops to 0.86 in the SLM trim. In the area between the end of row 1 and start of row 2, there is a marginal drop in the normalised static pressure for both the trims. In the subsequent rows, a similar trend continues where the pressure drops further in stages in both the trims. It can be seen in Fig. 16 that there is a significant amount of pressure drop in row 3 of the SLM trim. At the exit of the fifth row, it has been found that the pressure in the EDM trim reduces to 
$50 \%$ of the trim inlet pressure (row 1 entry) whereas in the SLM trim it reduces to $25 \%$ of the inlet pressure.
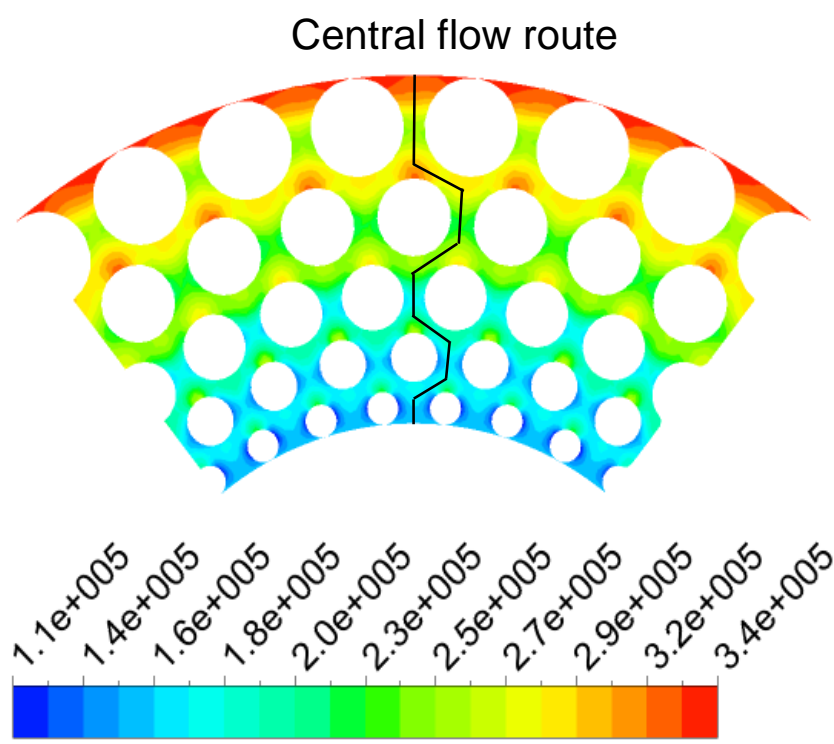

(a) EDM
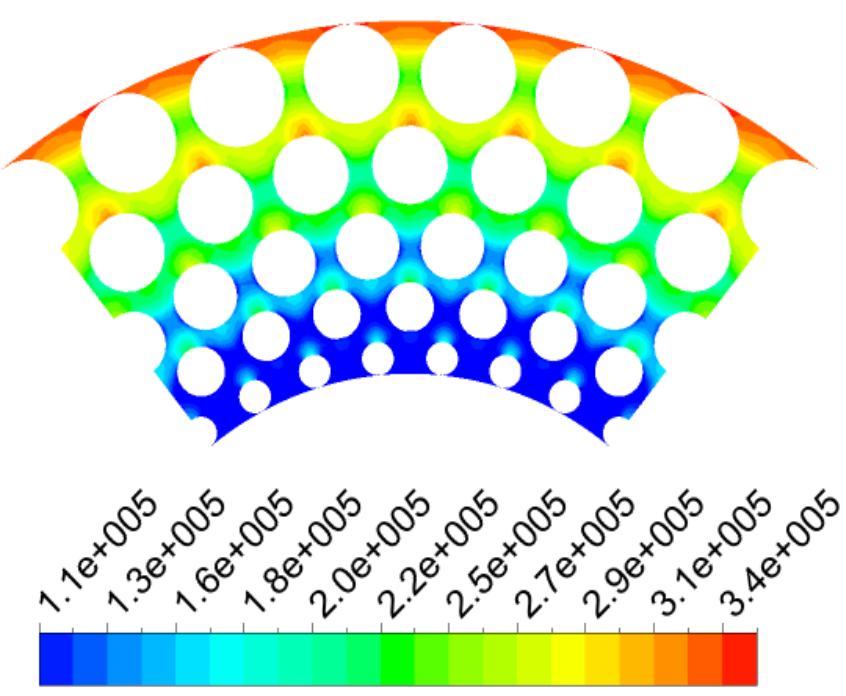

(b) SLM

Fig. 15. Static pressure $(\mathrm{Pa})$ variation at the top disc of the trims 


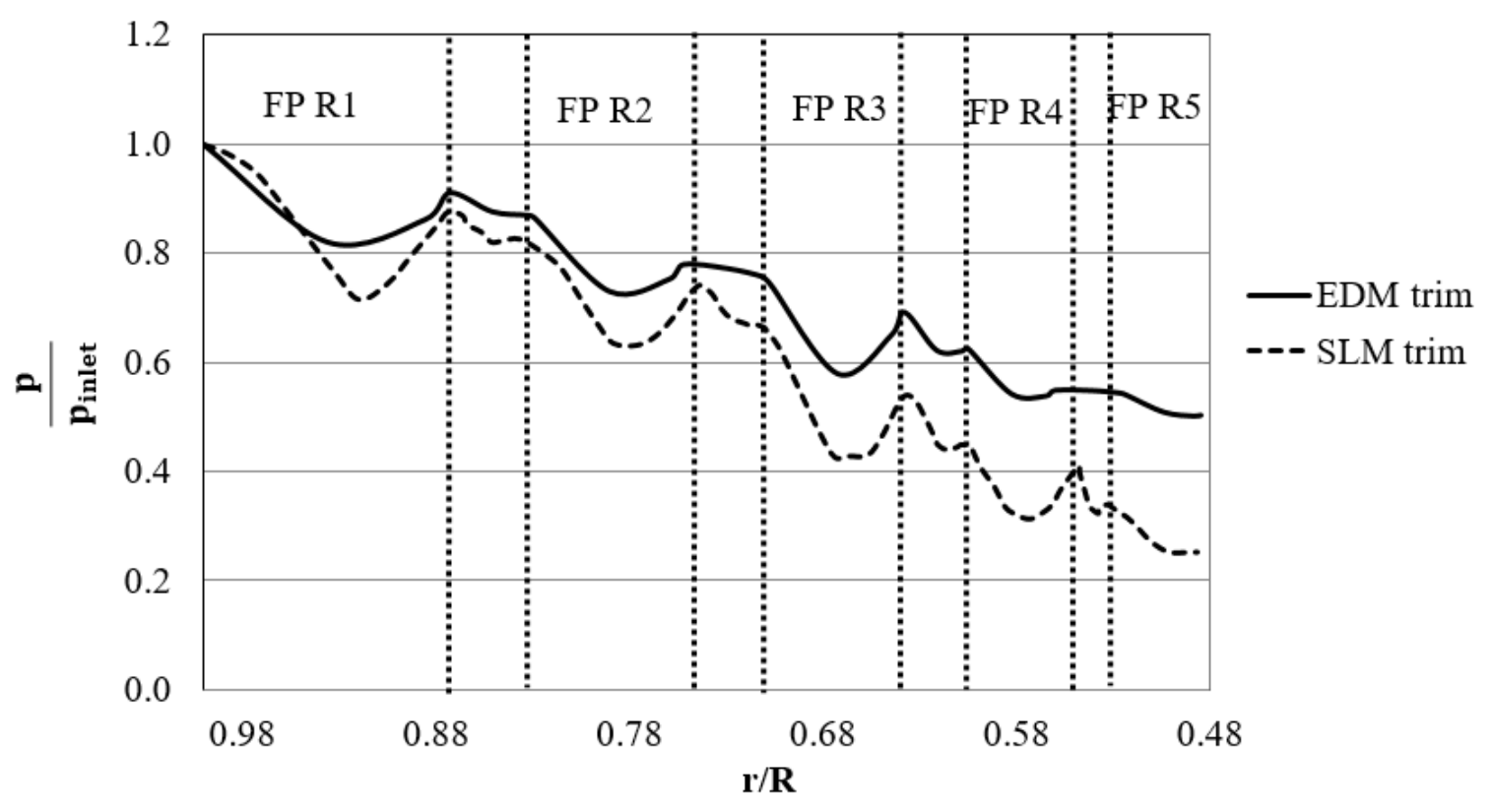

Fig. 16. Normalised static pressure variations within the top disc of the trims along the central flow route

The ratio of normalised static pressure variation of SLM and EDM trims along the central flow path has been presented in Fig. 17. The figure also shows that the pressure ratio decreases at a significantly higher rate in rows 3,4 and 5 than the first two rows. At the exit from the trim at the end of row 5, the normalised static pressure in SLM trim is half of that in the EDM trim.

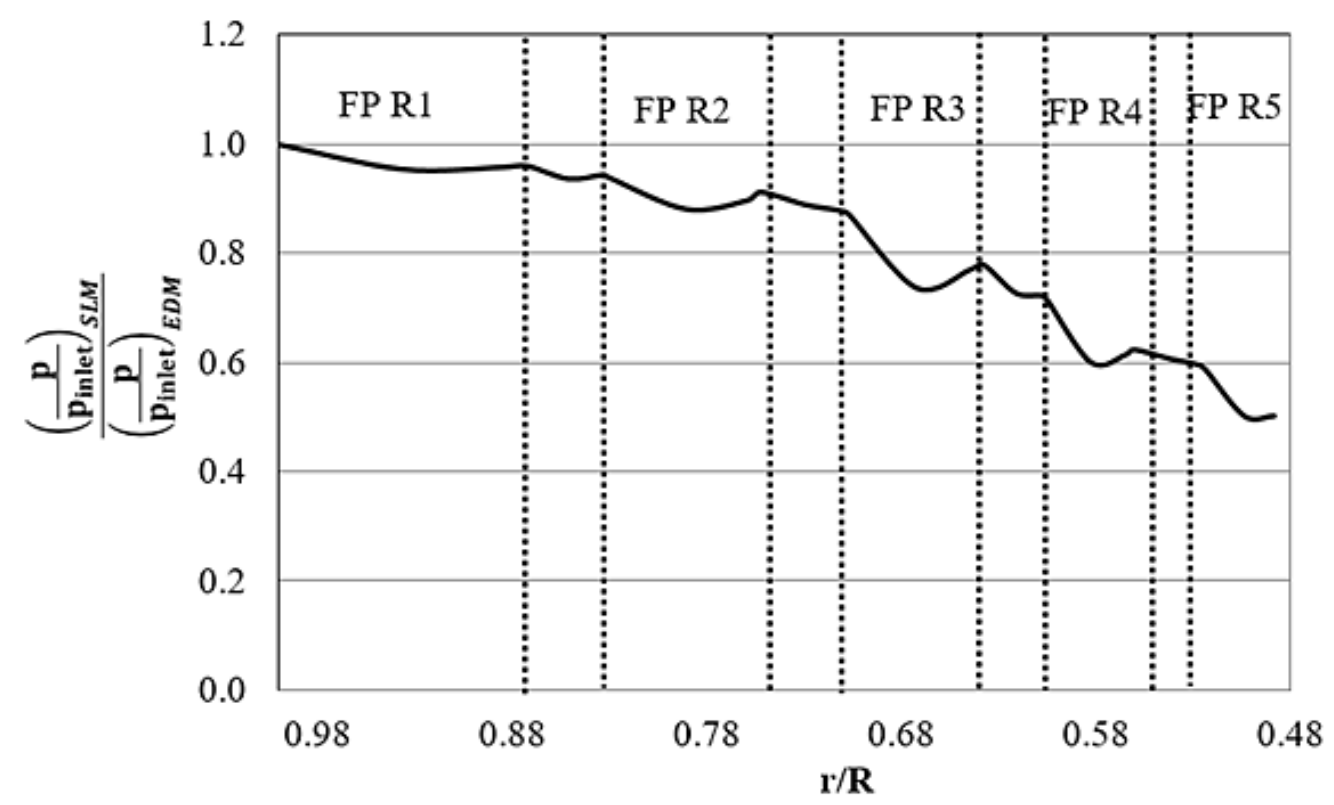

Fig. 17. Variations of normalised static pressure ratio between SLM and EDM trims along the central flow route

In order to compare the pressure drop across various rows of the disc, normalised differential pressure across each row along the central flow route is plotted in Fig. 18. It can be seen that the pressure drop is higher at each row in the SLM trim as outlined previously. For both the trims, the pressure drop is slightly lower in the second row as compared to the first row. The 
decreasing trend continues in row 3 for the EDM trim, however, it increases in the fourth row and then decreases again in the fifth row. On the other hand, for the SLM trim, the pressure drop in the third row is the highest after which it shows a decreasing trend. It was found that row 3 of the SLM trim contributes to $26 \%$ of the overall pressure drop across the top disc of the trim.

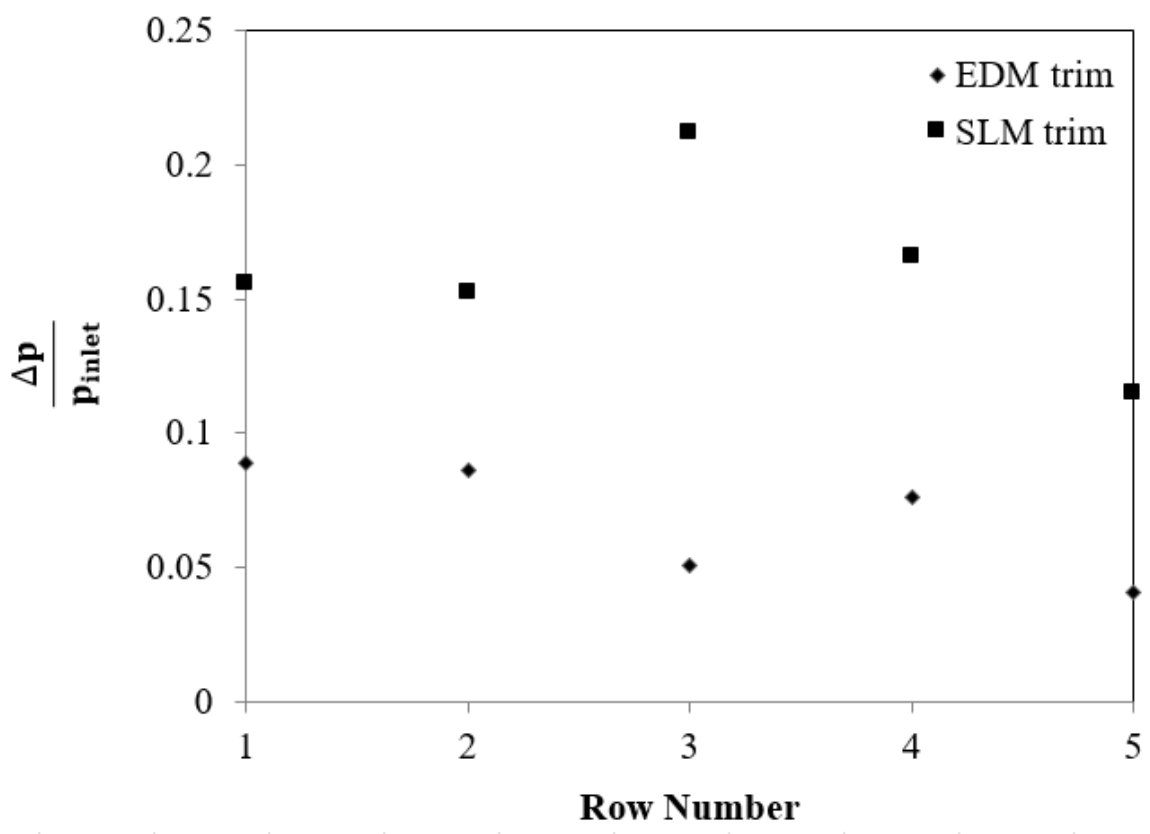

Fig. 18. Normalised differential static pressure across different rows at the central flow route within the top disc of the trims

Fig. 19 shows the ratio of normalised differential pressures of SLM and EDM trims at each

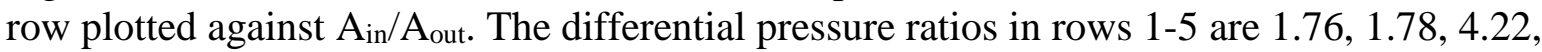
2.18 and 2.82 respectively, giving an average of 2.55 across all rows. It can be seen in the figure that the normalised differential pressure ratio decreases with increase in $A_{\text {in }} / A_{\text {out }}$, except row 3, where it is the highest. Abnormal flow behaviour at row 3 of this kind of trim was also reported by Asim et al. [29] while investigating the pressure losses per unit radial distance. The next highest point in the graph is at row 5. The pressure drop across the flow paths is the combined effect of geometrical features of the flow paths as well as the surface roughness. Previous papers by Asim et al. [16,17] have discussed the effect of the geometrical features on the pressure drop across the flow paths and they showed how change in the geometrical features affected the pressure drop across each flow path for EDM manufactured trims. In the present paper, the geometrical features of both the trims are similar to those used by Asim et al., therefore, Figs. 16-19 show how the variation of surface roughness affects the pressure drop across each flow path. 


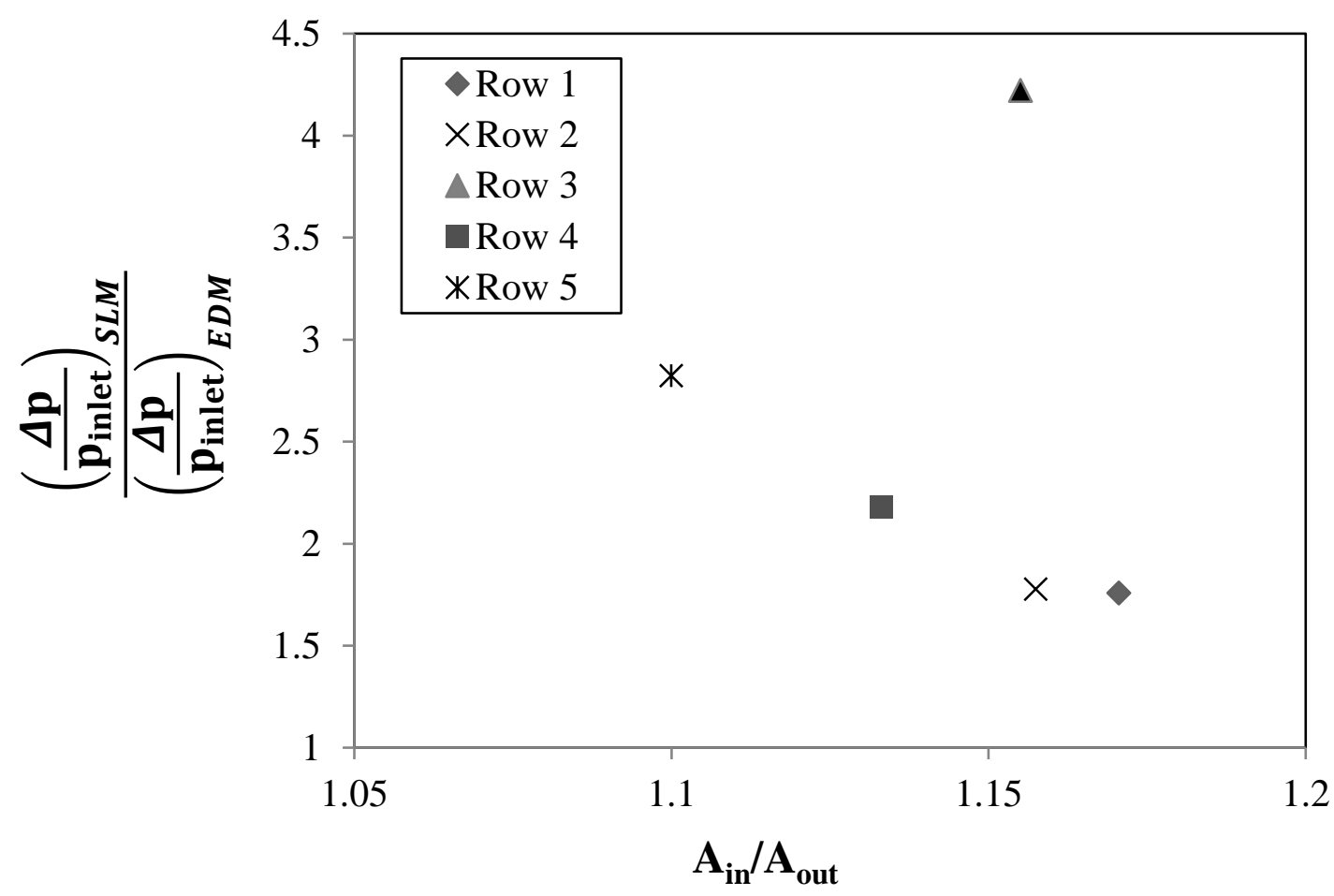

Figure 19. Normalised differential static pressure ratio of SLM and EDM across different rows within the top disc

\subsection{Velocity variations}

After analysing the pressure variations for both the trims, velocity variations within the trims at the top disc are presented in this section. Fig. 20 shows the flow velocity magnitude contours at a quarter of the top disc of both the trims. It can be seen from the figure that after entry in each row of the trim, the flow velocity increases as it passes the narrow area between the cylinders in a row and then decreases with increase in the flow area towards the exit of each row. The maximum velocity of the fluid in the EDM trim along the central flow path is each row is $12 \mathrm{~m} / \mathrm{s}$ (Row 1), $11.5 \mathrm{~m} / \mathrm{s}$ (Row 2), $12.7 \mathrm{~m} / \mathrm{s}$ (Row 3), $11 \mathrm{~m} / \mathrm{s}$ (Row 4) and 9.9 $\mathrm{m} / \mathrm{s}$ (Row 5), whereas in the SLM trim, the maximum flow velocity in each row is $8.9 \mathrm{~m} / \mathrm{s}$ (Row 1), $8.93 \mathrm{~m} / \mathrm{s}$ (Row 2), $10.3 \mathrm{~m} / \mathrm{s}$ (Row 3), $9.3 \mathrm{~m} / \mathrm{s}$ (Row 4) and $6.8 \mathrm{~m} / \mathrm{s}$ (Row 5). Thus, it can be seen that the flow velocities are higher in the EDM trim as compared to the SLM trim due to the reason that in the SLM trim, the resistance to flow is greater due to its greater surface roughness. These simulations were conducted for a similar pressure drop which resulted in lower flow rate with the SLM trim case which results in the lower flow velocities in the flow paths. The reduction in maximum flow velocities in the SLM trim from rows 1-5 is $11.2 \%, 11.2 \%, 9.7 \%, 10.8 \%$ and $14.7 \%$ respectively. 

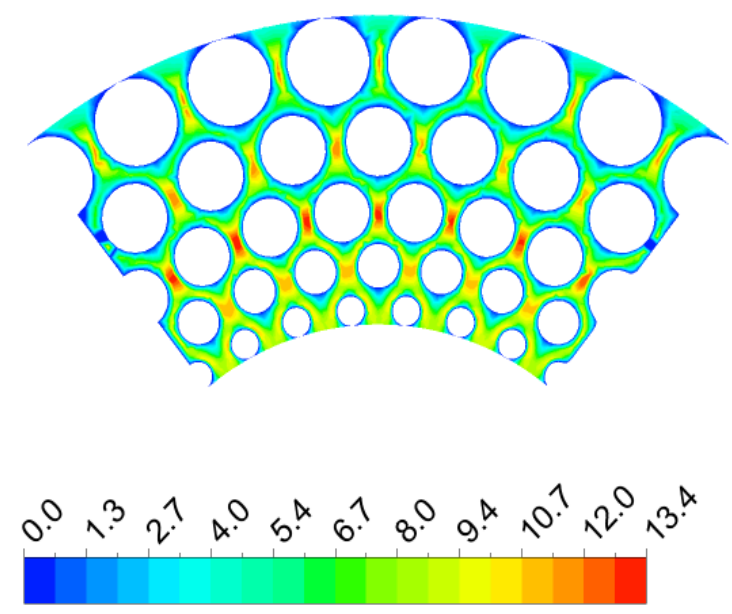

(a) EDM
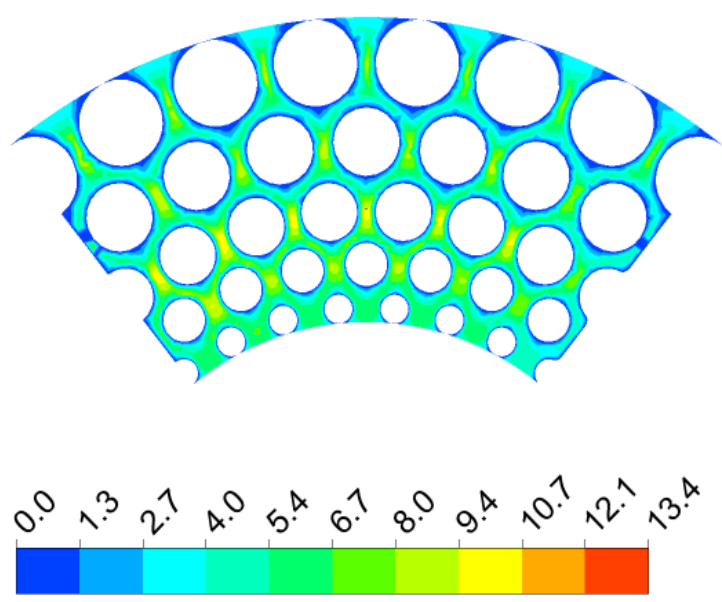

(b) SLM

Fig. 20. Velocity $(\mathrm{m} / \mathrm{s})$ variation within the top disc of the trims

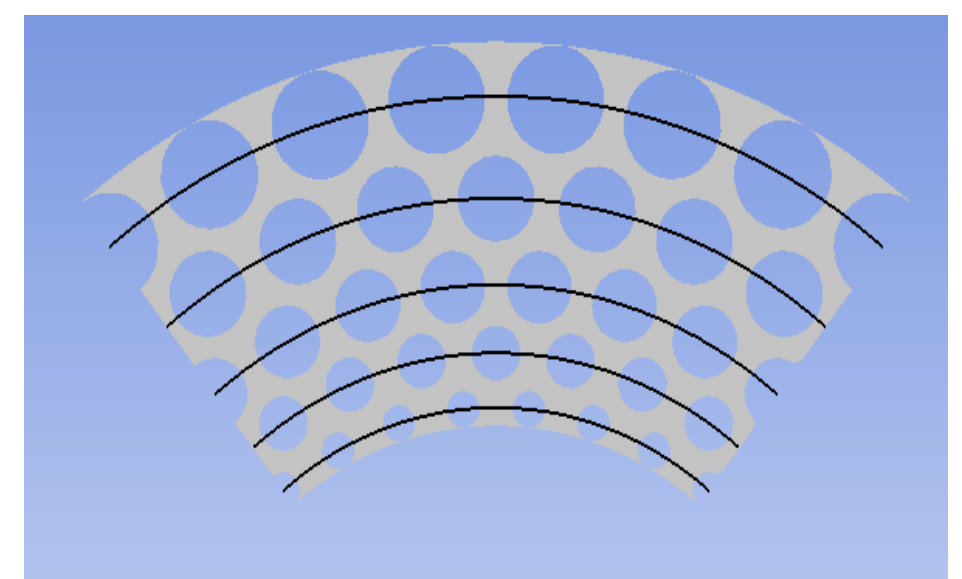

Fig. 21. Arcs in the middle of each row for velocity profile extraction

Flow velocity was extracted at an arc passing through each row of the discs as shown in Fig. 21 for analysing the flow velocity further. The normalised velocity profiles at each row are presented in Figs. 22 and 23. Due to the reason that rows 1, 3 and 5 have seven flow paths 
and rows 2 and 4 have eight flow paths, these have been presented separately. Velocity magnitude $(\mathrm{u})$ at the arc passing through the centre of each row of cylinders has been normalised by the maximum flow velocity $\left(U_{\max }\right)$ achieved in each trim. The $\mathrm{x}$ axis shows the normalised angular location in terms of $\phi$ and $\theta$, where $\phi$ is the local angular location and $\theta$ is $77^{\circ}$ (angle covered by the disc quarter). It can be seen in the figures that at each flow path, the flow velocity is maximum at the centre of the flow path and zero at the walls.

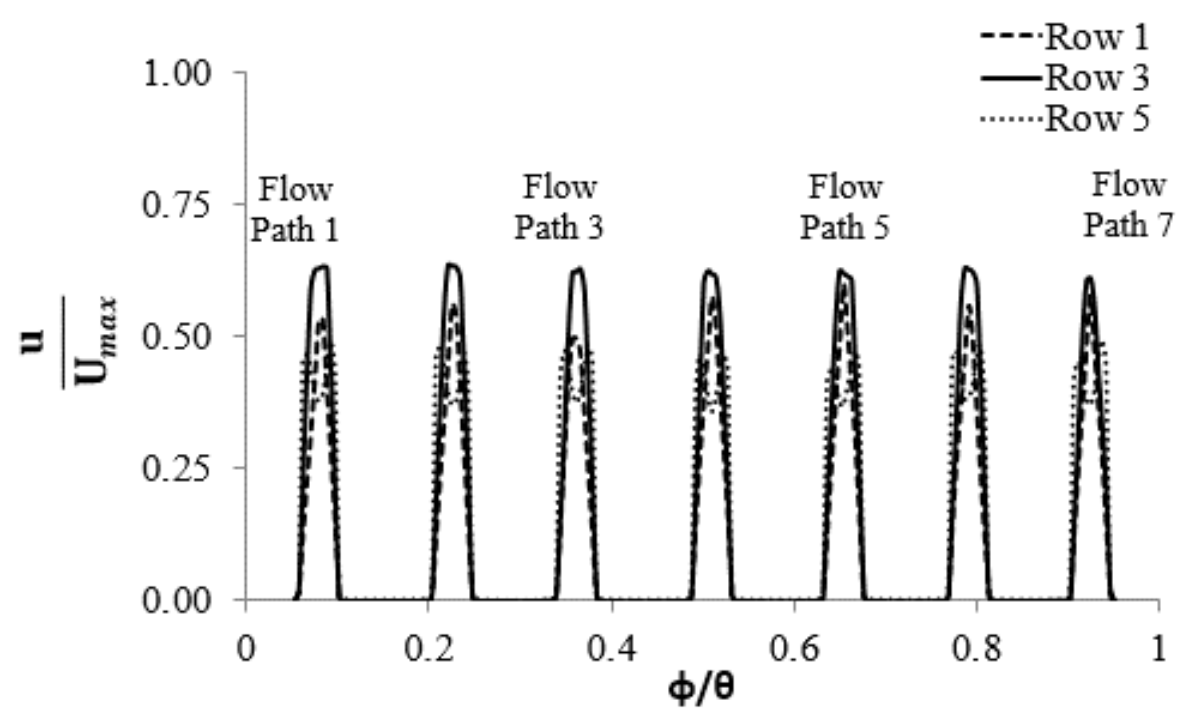

(a) EDM

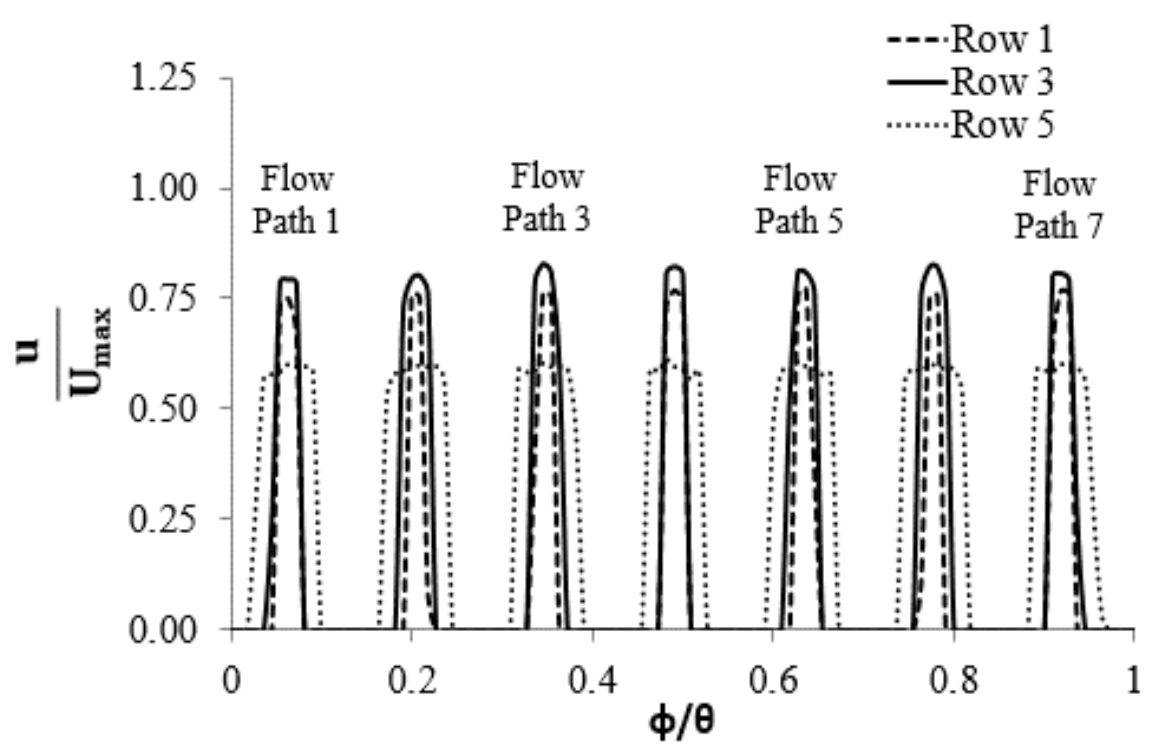

(b) SLM

Fig. 22. Normalised velocity profiles at rows 1,3 and 5 at the top disc of both trims

It can be seen from Fig. 22 that for rows 1, 3 and 5, the maximum normalised flow velocity is $0.6,0.63$ and 0.49 respectively for the EDM trim while for the SLM trim, it is 0.77, 0.83 and 0.61 respectively. Fig. 23 shows that at rows 2 and 4, the maximum normalised flow velocity is 0.57 and 0.55 respectively for the EDM trim while for the SLM trim, it is 0.73 and 0.7 respectively. Thus, the normalised flow velocity is maximum at row 3 for both the trims 
because row 3 has the smallest available flow area. In contrast, the normalised flow velocity is minimum at row 5 because it has the maximum flow area. The flow velocity variation patterns in different flow paths within each row are similar except first and last flow paths of row 2 and 4 because of their different geometry as compared to other flow paths.

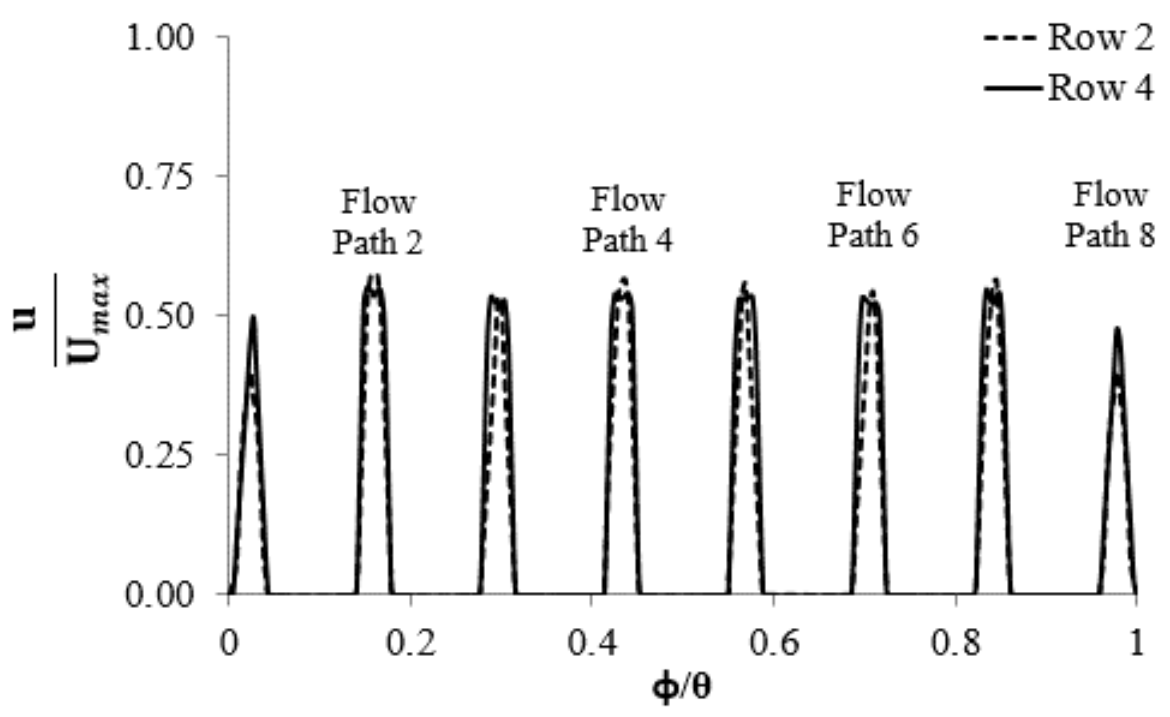

(a) EDM

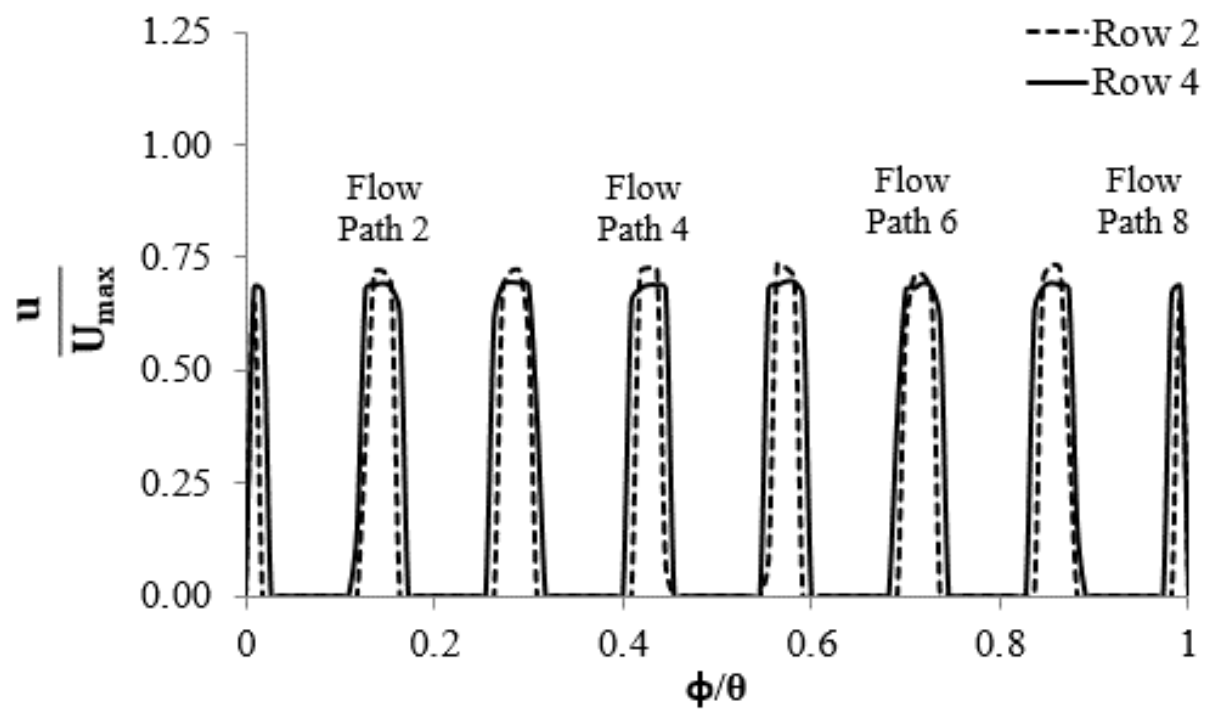

(b) SLM

Fig. 23. Normalised velocity profiles at rows 2 and 4 at the top disc of both trims 


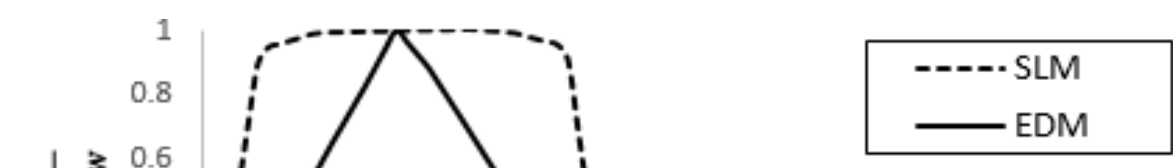

Row 1 "

Row 2
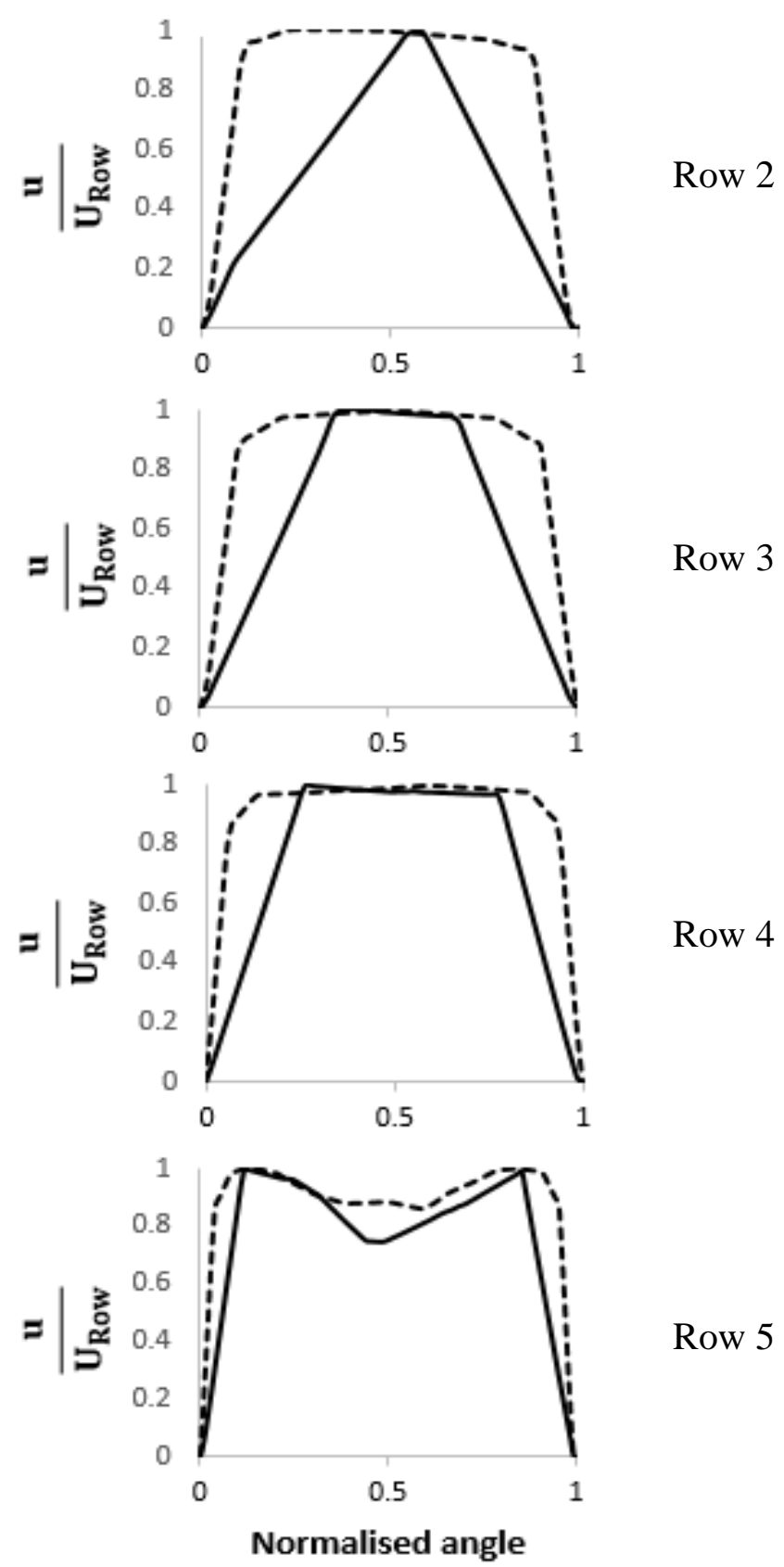

Figure 24. Normalised velocity profiles in each row along the central flow path for both trims 
The normalised velocity profile in the central flow paths in each row is depicted in Fig. 24 for both the EDM and SLM trims, where, $\mathrm{U}_{\text {Row }}$ is the maximum velocity in the row. It can be seen that the velocity profile in the SLM trim becomes flatter due to the effect of the increased surface roughness. For the EDM trim, the velocity profile is the peaky in the first two rows and it becomes flatter as it goes along the flow paths in subsequent rows on the disc. The velocity profile in row 5 of both trims shows two peaks and a dip in the middle. The location of these high velocity regions in row 5 can be seen in Fig. 20 along the sides of the cylinders in row 5. Furthermore, the gradient of velocity change with increasing distance from the wall is greater for the SLM trim as comparted to the EDM trim.

\subsection{Boundary shear}

It has been shown in the previous sections that the performance of the valve trim decreased with the change of surface finish/roughness. The reason for the drop in performance is because of the increased boundary shear due to the increased surface roughness. In order to present the effect of roughness, wall shear stress has been calculated for each flow path along the central flow route. Fig. 25 shows the average wall shear stress at the flow paths in each row in both the trims. It can be seen that the wall shear stress is higher in all the rows in the SLM trim as compared to the EDM trim because of the higher surface roughness. The highest wall shear stress occurs at row 4 whereas the lowest wall shear stress occurs at row 1 for both the trims. On average, the wall shear stress in the SLM trim is 1.9 times higher than the EDM trim. The trend in the wall shear stress is similar for both the trims across different rows.

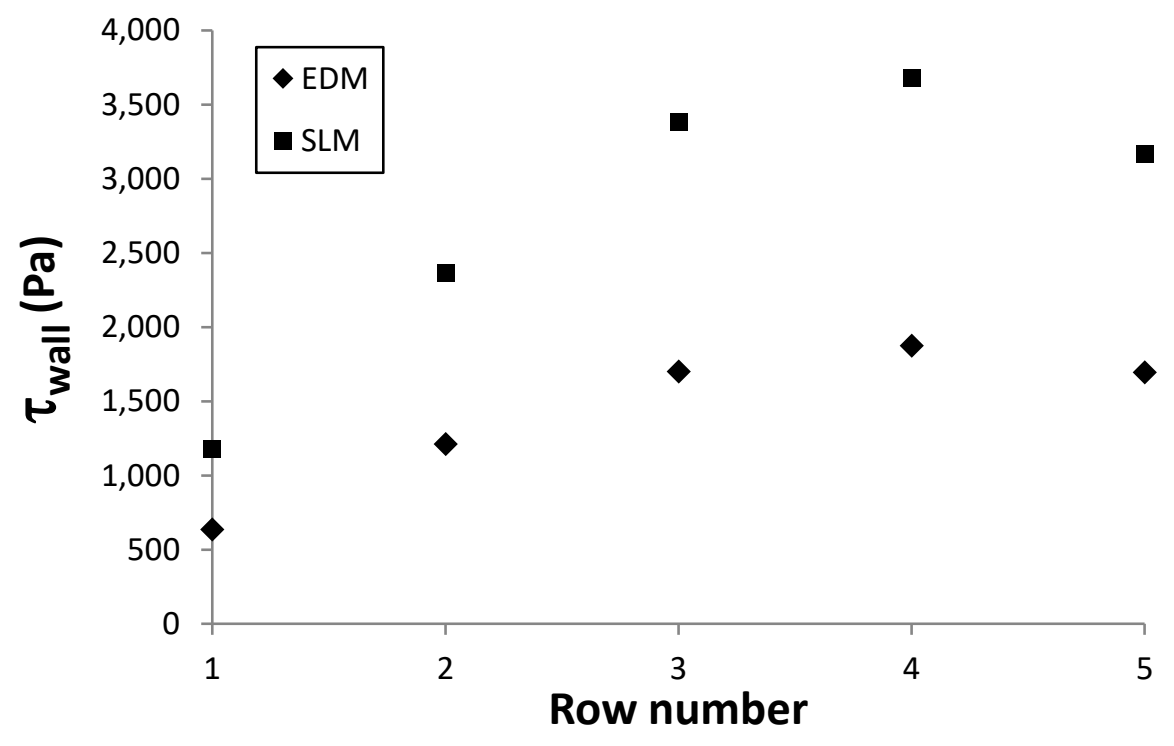

Fig. 25. Wall shear stress along the central flow path at different rows of EDM and SLM trims

The ratios of wall shear stress between the SLM and EDM trims at each row are plotted in Fig. 26. The wall shear stress ratio can be seen to vary from 1.85 to 1.99 between different rows of the trims and it is seen to be maximum at row 3 . The wall shear stress ratio is minimum at row 1 which then increases in row 2 and 3 and then drops in rows 4 and 5 . This explains the reason for the highest pressure drop occurring in row 3 of the SLM trim. 


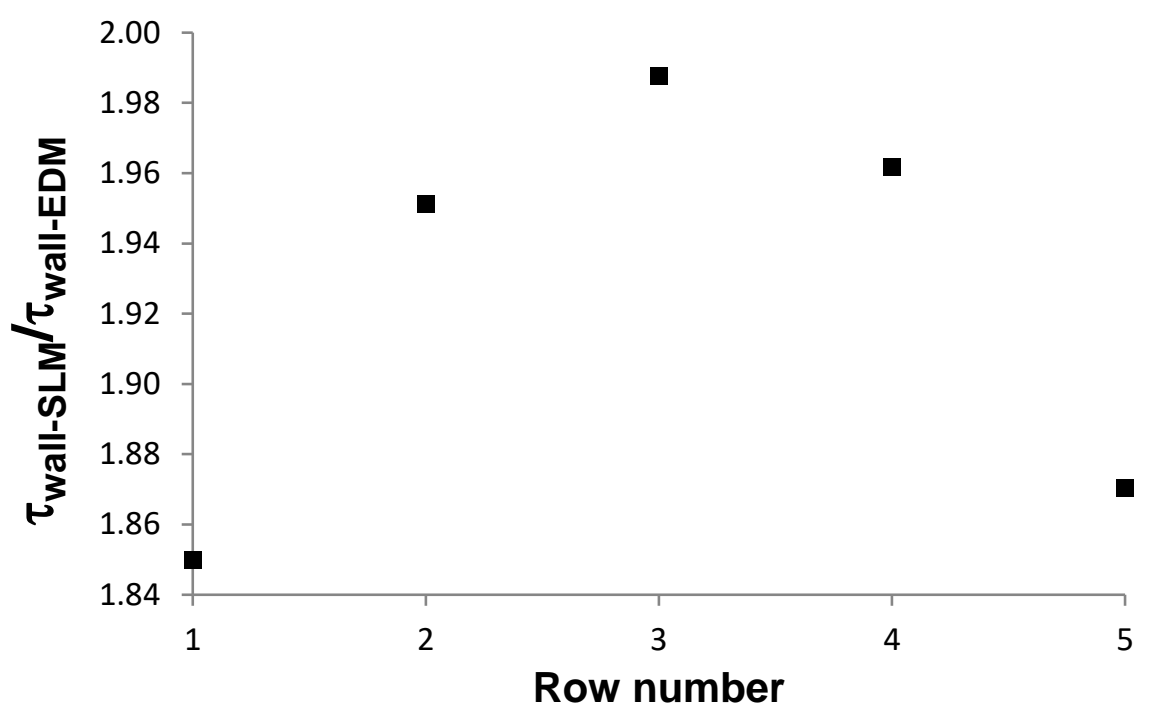

Figure 26. Wall shear stress ratio of SLM to EDM trim at each row along the central flow path

Thus, the analysis of results from CFD simulations have shown how the change in surface roughness due to manufacturing method has changed the local flow parameters, such as pressure, velocity and wall shear stress on the flow paths of the trims. The Sdr parameter for the SLM trim was 2.8 times and the Sa was four times of that for the EDM trim. Increase in surface roughness lead to an increase in the wall shear stress of 1.9 times on average across all the rows of the trim. The maximum pressure drop has been observed to occur at row 3 of the SLM trim which is due to the highest increase in the wall shear stress occurring at row 3 as seen in Fig. 26. However, the maximum decrease in the local flow coefficient has been noticed at row 5 where the differential pressure drop ratio between the SLM and EDM trims is the second highest and the decrease in maximum velocity is the highest. Therefore, it has been seen that rows 3 and 5 are the highest contributors in the decrease in the performance of the trim manufactured using the SLM method.

The surface roughness of AM parts is highly re-entrant in nature and it is probable that conventional line of sight measured roughness parameters underestimate the scale of roughness and certainly would underestimate the real surface area [30]. Enabling the reentrant nature to be included in model could enhance the accuracy of the modelling.

The above results indicate that although the additive manufacturing methods offer significant advantages in the manufacturing processes, the effectiveness of products manufactured needs to be carefully investigated. This is particularly true for flow handling equipment as it may have both local as well as global effects.

\section{Conclusion}

The traditional method of EDM requires a significant amount of time and cost to manufacture a complex geometry multi-stage disc stack trim. Therefore, in order to reduce costs of manufacturing, a valve trim was manufactured by employing the additive manufacturing method of SLM and its performance was tested. The experimental testing of the trim showed performance of the trim was reduced as compared to the EDM manufactured trim due to the 
higher surface roughness of the SLM manufactured valve trim. Local performance analysis using CFD showed that the rows 3 and 5 of the SLM trim to be the highest contributors to the decrease in the flow capacity of the trim because the pressure drop ratios are higher in these rows as compared to the EDM trim. The increase in pressure drop in the SLM trim is due to the wall shear stress increase in the SLM trim because of the higher surface roughness. On average, the wall shear stress in the SLM trim has been found to be 1.9 times higher than the EDM trim. Despite the shortcomings in performance, the SLM trim was manufactured in a considerably shorter time and a cost reduction of 50\% was achieved as compared with the trim manufactured by EDM. Finishing processes have been developed that can reduce the roughness of complex AM parts however their effectiveness in reducing roughness in complex parts and the effect on changing the geometry of the trim elements needs further study [31]. Consequently, the additive manufacturing method of SLM with additional finishing is possibly still viable commercially.

\section{References}

[1] M. Charlton, Cost effective manufacturing and optimal design of X-stream trims for severe service control valves, MSc Thesis, University of Huddersfield, 2014.

[2] M. Charlton, R. Mishra, T. Asim, The effect of manufacturing method induced roughness on severe service control valve performance, in: Proc. 6th Int. 43rd Natl. Conf. Fluid Mech. Fluid Power, 2016.

[3] M.K. Thompson, G. Moroni, T. Vaneker, G. Fadel, R.I. Campbell, I. Gibson, A. Bernard, J. Schulz, P. Graf, B. Ahuja, F. Martina, Design for Additive Manufacturing: Trends, opportunities, considerations, and constraints, CIRP Ann. 65 (2016) 737-760. doi:10.1016/j.cirp.2016.05.004.

[4] D. Herzog, V. Seyda, E. Wycisk, C. Emmelmann, Additive manufacturing of metals, Acta Mater. 117 (2016) 371-392. doi:10.1016/j.actamat.2016.07.019.

[5] Q.B. Nguyen, D.N. Luu, S.M.L. Nai, Z. Zhu, Z. Chen, J. Wei, The role of powder layer thickness on the quality of SLM printed parts, Arch. Civ. Mech. Eng. 18 (2018) 948955. doi:10.1016/J.ACME.2018.01.015.

[6] S. Tsopanos, Micro heat exchangers by selective laser melting, $\mathrm{PhD}$ thesis, University of Liverpool (2008).

[7] R.K. Enneti, R. Morgan, S. V. Atre, Effect of process parameters on the Selective Laser Melting (SLM) of tungsten, Int. J. Refract. Met. Hard Mater. 71 (2018) 315-319. doi:10.1016/J.IJRMHM.2017.11.035.

[8] P. Hanzl, M. Zetek, T. Bakša, T. Kroupa, The Influence of Processing Parameters on the Mechanical Properties of SLM Parts, Procedia Eng. 100 (2015) 1405-1413. doi:10.1016/J.PROENG.2015.01.510.

[9] K. Osakada, M. Shiomi, Flexible manufacturing of metallic products by selective laser melting of powder, Int. J. Mach. Tools Manuf. 46 (2006) 1188-1193. doi:10.1016/J.IJMACHTOOLS.2006.01.024.

[10] B.N. Turner, S.A. Gold, A review of melt extrusion additive manufacturing processes: II. Materials, dimensional accuracy, and surface roughness, Rapid Prototyp. J. 21 (2015) 250-261. doi:10.1108/RPJ-02-2013-0017.

[11] S. Thamizhmanii, S. Saparudin, S. Hasan, Analyses of surface roughness by turning process using Taguchi method, J. Achiev. Mater. Manuf. Eng. 20 (2007) 503-505. doi:10.1007/s00170-007-1147-0. 
[12] L. Blunt, X. Jiang, Advanced techniques for assessment of surface topography, Kogan Page Science, 2003.

[13] J.B. Taylor, A.L. Carrano, S.G. Kandlikar, Characterization of the effect of surface roughness and texture on fluid flow-past, present, and future, Int. J. Therm. Sci. 45 (2006) 962-968. doi:10.1016/j.ijthermalsci.2006.01.004.

[14] J. Green, R. Mishra, M. Charlton, R. Owen, Validation of CFD predictions using process data obtained from flow through an industrial control valve, J. Phys. Conf. Ser. 364 (2012) 012074. doi:10.1088/1742-6596/364/1/012074.

[15] T. Asim, R. Mishra, M. Charlton, C. Oliveira, Capacity Testing and Local Flow Analysis of a Geometrically Complex Trim Installed within a Commercial Control Valve, in: Int. Conf. Jets, Wakes Separated Flows, Stockholm, Sweden, 2015.

[16] T. Asim, M. Charlton, R. Mishra, CFD based investigations for the design of severe service control valves used in energy systems, Energy Convers. Manag. 153 (2017) 288303. doi:10.1016/J.ENCONMAN.2017.10.012.

[17] T. Asim, R. Mishra, A. Oliveira, M. Charlton, Effects of the geometrical features of flow paths on the flow capacity of a control valve trim, J. Pet. Sci. Eng. 172 (2019) 124-138. doi:10.1016/J.PETROL.2018.09.050.

[18] A. Oliveira, Capacity testing of X-stream valves for single-component single-phase flows, Report submitted to Weir Valves and Controls, UK (2017).

[19] X. Sun, H.S. Kim, S.D. Yang, C.K. Kim, J.Y. Yoon, Numerical investigation of the effect of surface roughness on the flow coefficient of an eccentric butterfly valve, J. Mech. Sci. Technol. 31 (2017) 2839-2848. doi:10.1007/s12206-017-0527-0.

[20] D. Singh, M. Charlton, T. Asim, R. Mishra, Design for additive manufacturing and its effect on the performance characteristics of a control valve trim, Int. J. COMADEM. 22 (2019) 59-67.

[21] British Standards Institute, BS EN 60534-2-3 (1998) Industrial-process control valves. Part 2-3: Flow capacity - Test procedures., (1998).

[22] T. Asim, Capacity testing of x-stream valves for single-component single-phase flows, Report submitted to Weir Valves and Controls, UK (2013).

[23] A. Townsend, N. Senin, L. Blunt, R.K. Leach, J.S. Taylor, Surface texture metrology for metal additive manufacturing: a review, Precis. Eng. 46 (2016) 34-47. doi:10.1016/J.PRECISIONENG.2016.06.001.

[24] E. Palmer, R. Mishra, J. Fieldhouse, A computational fluid dynamic analysis on the effect of front row pin geometry on the aerothermodynamic properties of a pin-vented brake disc, Proc. Inst. Mech. Eng. Part D J. Automob. Eng. 222 (2008) 1231-1245. doi:10.1243/09544070JAUTO755.

[25] A. Shahzad, T. Asim, R. Mishra, A. Paris, Performance of a Vertical Axis Wind Turbine under Accelerating and Decelerating Flows, Procedia CIRP. 11 (2013) 311-316. doi:10.1016/j.procir.2013.07.006.

[26] K. Park, T. Asim, R. Mishra, Computational Fluid Dynamics based Fault Simulations of a Vertical Axis Wind Turbines, J. Phys. Conf. Ser. 364 (2012) 012138. doi:10.1088/1742-6596/364/1/012138.

[27] B. Tesfa, F. Gu, R. Mishra, A.D. Ball, LHV predication models and LHV effect on the performance of CI engine running with biodiesel blends, Energy Convers. Manag. 71 (2013) 217-226. doi:10.1016/j.enconman.2013.04.005.

[28] Ansys Inc, Ansys Fluent 17 User Guide, (2015).

[29] T. Asim, A. Oliveira, M. Charlton, R. Mishra, Improved design of a multi-stage continuous-resistance trim for minimum energy loss in control valves, Energy. 174 (2019) 954-971. doi:10.1016/j.energy.2019.03.041.

[30] A. Townsend, L. Pagani, P.J. Scott, L. Blunt, Introduction of a Surface Characterization 
Parameter Sdrprime for Analysis of Re-entrant Features, J. Nondestruct. Eval. 38 (2019) 58. doi:10.1007/s10921-019-0573-x.

[31] A. Diaz, L. Winkleman, J. Michaud, C. Terrazas, Surface Finishing and Characterization of Titanium Additive Manufacturing Components: From Rich to Smooth Surface, in: Eur. Congr. Exhib. Powder Metall. Eur. PM Conf. Proc., Hamburg, 2016: p. 6. 